\title{
Estado y ferrocarriles en México y EU, 1890-1911*
}

Arturo Grunstein INSTITUTO MORA

\author{
Una reflexión comparativa, en la que se destaca la acción \\ estatal en el auge ferrocarrilero.
}

\section{INTRODUCCIÓN}

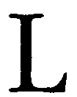

a política ferrocarrilera del porfiriato ha desatado polémica en diversos trabajos académicos. Sin embargo, mientras que algunos puntos han sido exhaustivamente estudiados, otros aún no se investigan. Por ello,existe mucha información de las primeras etapas de la construcción, sobre todo de 1880 a 1890 , pero en cambio se sabe muy poco de la política ferrocarrilera seguida en los últimos años del porfiriato.

No obstante, de este último periodo existe un área que ha llamado mucho la atención: el proceso de consolidación de las principales líneas bajo la propiedad mayoritaria del gobierno, mismo que se inició en 1902 y culminó en 1908 con la formación de Ferrocarriles Nacionales de México. De hecho, la compra de acciones y la obtención del control de los ferrocarriles por el gobierno han sido algunos de los puntos más controvertidos de la política económica porfiriana. ${ }^{1}$

En muchos casos, el interés por el tema ha surgido del hecho de que la

"Agradezco a las fundaciones Hewlett, Mellon y al Social Science Research Council su apoyo económico para esta investigación.

${ }^{1}$ Consultar, por ejemplo, a Calderón, "Ferrocarriles", 1965; Coatsworth, Impacto, 1984; Díaz Dufoo, Limantour, 1910; Fuentes Díaz, Problema, 1951; González Roa, Problema, 1915; Gurza, Política, 1911; López Gallo, Economía, 1988; Macneely, Railways, 1964; Ortiz Hernán, Ferrocarriles, 1987; Parlee, Porfirio, 1981; Randall, "Mexico's", 1985. 
adquisición del ferrocarril por el gobierno precediera al ascenso del Estado nacionalista y activista que siguió a la revolución mexicana ${ }^{2}$ Las razones, la ideología y los motivos de la consolidación del gobierno como dueño de las vías férreas más importantes han sido el meollo de esta discusión sin respuestas que se remonta al porfiriato. ${ }^{3}$

Los objetivos de este trabajo son, primero, sugerir un punto de vista alternativo, y, segundo, formular una posible reinterpretación de la política ferrocarrilera del porfiriato tardío, haciendo énfasis en su consolidación bajo propiedad gubernamental. Pocos autores han podido entender la lógica de la intervención del gobierno en el sector ferrocarrilero durante la última década del porfiriato. En pocas palabras, yo creo que en la mayoría de los análisis se le ha puesto demasiada atención al punto en que se contraponen los intereses nacionales a los extranjeros, y por ello se ha perdido la visión de la complejidad en la política ferrocarrilera del porfiriato.

Propongo analizar la formación de Ferrocarriles Nacionales de México y la

\footnotetext{
${ }^{2}$ Consultar a Coatsworth, Impacto, 1984, p. 44. Alan Knight sostiene que el nacionalismo económico "no era una virtud caracteristica del pensamiento revolucionario original" y que de hecho "se acerca a los antecedentes porfirianos, e incluso al gabinete de Porfirio Díaz", Knight, "Political", 1985 , p. 293. Knight incluye "la creación de Limantour de los Ferrocarriles Nacionales", como uno de los principales ejemplos para probar que "el porfiriato tardío [...] fue testigo del modesto florecimiento de un nacionalismo económico, como prueba de que el modelo cientifico era, hasta cierto punto, pragmático y evolutivo, y por lo tanto, capaz de responder a los cambios a largo plazo en la economía y a su relación con el capital extranjero-prueba también de que la política científica no era simplemente un generoso regalo para los explotadores extranjeros". Knight, U.S., 1987, pp.72-73. Consultar también a Hart, Revolutionary, 1987, p. 248.

${ }^{3}$ Ibid.
}

política ferroviaria en general del fin del porfiriato considerando una serie de aspectos de las operaciones y políticas que se siguieron y que durante mucho tiempo se han ignorado en la historiografía ferrocarrilera mexicana. Estos aspectos son los siguientes:

Primero, las características económicas y los problemas estructurales de la industria ferroviaria como la primera gran empresa moderna; segundo, la influencia de las características estructurales y sus problemas en el desarrollo de la organización de la industria ferrocarrilera; tercero, el impacto que tuvieron las diferentes formas de intervención del gobierno en el desarrollo de esta organización y, por último, cómo afectó a su vez la evolución de la industria ferroviaria al gobierno en sí.

Examino estos puntos dentro del contexto histórico mexicano específico y del proceso que durante el periodo final del porfiriato dio pie a la formación de Ferrocarriles Nacionales de México. Para esto utilizo fuentes de información de primera mano que han sido olvidadas o tan sólo se han estudiado superficialmente. Acepto que muchos aspectos siguen sin esclarecerse, pero mi intención es, en realidad, demostrar la utilidad de este análisis alternativo en la identificación de los puntos críticos y los problemas que explican la urgencia del gobierno de México de los últimos años del porfiriato por poseer la industria ferroviaria.

\section{UN ENFOQUE ALTERNATIVO: LA IMPORTANCIA DE LA ECONOMÍA FERROCARRILERA Y ALGUNOS EJEMPLOS TOMADOS DE LA HISTORIOGRAFIA FERROVIARIA DE ESTADOS UNIDOS}

Como se sugirió previamente, la mayoría de los análisis de las causas y de las formas en que intervino el gobierno del 


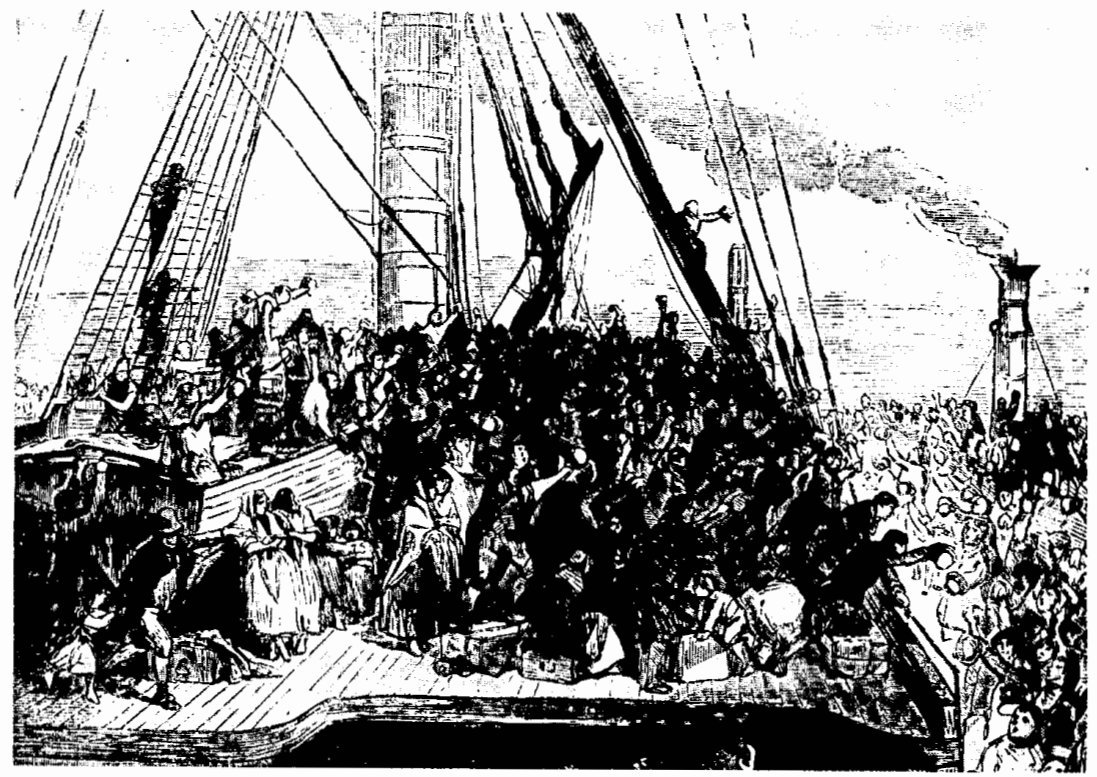

porfiriato tardío ignoran el papel que jugó la economía ferrocarrilera en la decisión del gobierno de adquirir la propiedad de los ferrocarriles entre 1902 y 1910.

Me di cuenta de la importancia de estas características económicas gracias a la historiografia ferrocarrilera de Estados Unidos.

Siendo la primera industria moderna intensiva de capital (en casi todos los países), los ferrocarriles tuvieron queenfrentar determinados problemas estructurales asociados con sus patrones característicos de precios y competencia. Los ferrocarriles incurrían en altos costos fijos por construcción, maquinaria, edificios, terrenos, etc., que por definición tenían que cubrirse como mantenimiento aunque en realidad no se hiciera uso de ellos. La proporción relativamente alta de estos costos fijos (en general era el $60 \%$ de los costos fijos) ejercía una gran presión en los ferrocarriles, "especialmente durante los tiempos de depresión en que para atraer tráfico se daban precios bajos". " Los recursos se tenían que aprovechar al máximo para evitar el alza excesiva en los costos unitarios.

Los historiadores han demostrado que

la combinación de costos fijos altos y la necesidad de maximizar la utilización de los recursos llevó a la industria ferroviaria [de Estados Unidos] a un estado caótico e inestable, con cuotas que fluctuaban ampliamente con el tiempo y según la región.

Dentro del contexto de los mercados concentrados y oligopólicos, la libre competencia en la industria ferroviaria

\footnotetext{
4 Yeager, Competition, 1981, p. 28

s lbid.
} 
era necesariamente interdependiente y frecuentemente acababa en pleitos destructivos.

\begin{abstract}
A diferencia de la competencia de precios entre empresas pequeñas en mercados no concentrados, que sencillamente orilló a los negocios poco eficientes a salir del mercado, la competencia oligopólica entre gigantes puede amenazar la sobrevivencia de toda la industria. ${ }^{6}$
\end{abstract}

Esto significa que como consecuencia de la competencia las tarifas de toda la industria finalmente caían por debajo del costo de los servicios. ${ }^{7}$ La constante disminución de las tarifas durante largos periodos resultó en la imposibilidad de que el capital invertido redituara adecuadamente, en infinidad de bancarrotas y en un severo deterioro de las vías férreas, dado que no existía capital con qué reponer lo que se iba gastando.

\section{Ibid.}

7 Deben explicarse más ampliamente las razones de por qué la competencia no estabiliza las tarifas al costo, sino que las reduce por debajo de él. Si todos los costos fueran variables, para una compañía no tendría sentido reducir sus tarifas por debajo del costo total de servicios. Sería mejor cerrar y permitir a otras líneas hacerse cargo del tráfico bajo esas condiciones, porque a más tráfico la pérdida sería mayor. Pero cuando buena partede los costos son fijos, y sólo unos cuantos variables, es preferible aceptar un tráfico que pague menos del costo total del servicio a permitir que lo transporte alguno de los competidores. El ferrocarril puede perder dinero al cobrar tarifas bajas, dado que los costos fijos se cubren tan sólo parcialmente, pero si no hay ningún tráfico entonces ni siquiera se cubre esa parte. En pocas palabras, es preferible transportar carga aunque se pierda un poco a no transportar nada'y perder todo.

Además de amenazar la viabilidad operativa y financiera, la "competencia destructiva" en Estados Unidos incluía la discriminación de precios como el arma más poderosa. Generaimente, la competencia dispareja acarreaba la discriminación. Llegaba un punto en que las tarifas se bajaban hasta niveles que no podian mantenerse si la línea pre-
Algunos historiadores de los ferrocarriles de Estados Unidos describen la evolución de esta industria durante la segunda mitad del siglo diecinueve como una serie de esfuerzos encaminados a solucionar la competencia ruinosa mediante diferentes planes de cooperación. ${ }^{8}$ En la literatura generalmente se le atribuye gran importancia a la interacción entre las actividades de los transportistas y el impacto de las reglas del gobierno para poder definir qué tanto éxito tuvieron cada uno de los métodos de cooperación y el desarrollo resultante de la organización de la industria ferroviaria.

La imagen que crea la historiografía presenta el fracaso de varias estrategias de las compañías (acuerdos informales sobre tarifas, asociaciones y pools desordenados, federaciones regionales y agencias de tarifas) que finalmente se combinaron y consolidaron en un sistema, comoúltimo recurso para restringiro reducir la competencia.

De acuerdo con algunos autores, los pools y otros métodos de acuerdo sobre tarifas no funcionaron en parte por la tendencia a romper los acuerdos sobre tarifas "en un mercado concentrado y oligopólico donde, cuando menos a corto plazo, reditúa más disminuir las tarifas para asegurar una buena participación del mercado". 9

tendia permanecer relativamente solvente. Si determinada situación no se prestaba a la competencia, entonces era motivo para cobrar tarifas propias de un monopolio. Las rebajas y concesiones generalmente eran of recidas a aquellos fletadores poderosos que estaban en posición de desviar el tráfico a otras lineas. Estas rebajas frecuentemente se hacían en secreto, para retardar las rebajas que en venganza ofrecían las líneas rivales. Locklin, Economics, 1954 , pp. 304-331.

${ }^{8}$ Ripley, Railroads, 1912 y Railroads, 1927; Lee Benson, Merchants, 1955; Kolko, Railroads, 1965; Macavoy, Economic, 1965; Chandler, Visible, 1977.

${ }^{9}$ Yeager, Competition, 1981, p. 28. 
Con todo, algunos historiadores como Albro Martin ${ }^{10}$ enfatizan lo negativo de la participación del gobierno al prohibir la formación de poolsen la Ley de Comercio Interestatal de 1887, bajo la intensa presión antimonopólica de los grupos interesados de fletadores y de legisladores "populistas-progresistas". Desde que la sección 5 de la Ley despojó de validez oficial la formación de pools, estos y otros acuerdos sobre las tarifas dependieron de la "estructuralmente" debilitada "buena fe" de los ferrocarrileros.

A principios de la década de 1890 , las constantes interrupciones en los acuerdos "convencieron por completo" a los ejecutivos de la industria ferroviaria de los Estados Unidos y a los banqueros inversionistas "de la inutilidad de la cooperación como medio de control para la competencia, aun contando con el apoyo del gobierno. En 1893 aceptaron que lo lógico era consolidarse. "11

Después de la depresión, de 1890 a 1900 los magnates y los hombres más importantes de esta industria, como lo fueron Harriman, Hill y Huntington, con la ayuda de banqueros como J. P. Morgan, Kohn, Loeb y Cía. y los hermanos Speyer "desarrollaron lo que llamaron 'comunidad de intereses' de los sistemas que operaban en la misma zona". ${ }^{12}$

Gabriel Kolko, historiador de la Nueva Izquierda, sugiere en su controvertida tesis que aun después de haberse consolidado la industria, permaneció "inherentemente competitiva" y que, por lo tanto, se vieron obligados a buscar una solución a través del gobierno. ${ }^{13}$ Según Kolko, el gobierno, aun bajo la administración progresista de 1900 , respondió favorablemente a las peticiones de los ferrocarrileros. Sostiene que la Comisión de Comercio Interestatal (CCI) funcionó como un cártel oficial para mantener las tarifas y las ganancias de los transportistas.

Esta tesis ha sido rebatida por muchos historiadores. ${ }^{14}$ Alfred D. Chandler, historiador de las empresas, critica a Kolko porque no se da cuenta de la eficacia de la integración de un sistema como alternativa a la formación de poolsy otros acuerdos sobre tarifas. Para Chandler, la reglamentación del gobierno no tuvo importancia en la resolución del problema de la competencia sin control en la industria ferroviaria. Concluye de la siguiente forma:

Para los ejecutivos ferroviarios de Estados Unidos, la solución a la competencia para lograr atraer tráfico entre algunas empresas grandes y con capital fuerte, fue la construcción de sistemas autosuficientes. Era la respuesta a la competencia, y no las necesidades u oportunidades para reducir costos mediante manejos administrativos, lo que llevó a incluir las actividades y transacciones de empresas, ya de por sí grandes, dentro de una misma megacorporación. Si el gobiemo hubiese sancionado la formación de pools la respuesta quizás hubiera sido diferente. A pesar de que los ferroviarios habían abogado por esta legislación entre 1870 y 1880 , ellos, junto con los banqueros inversionistas, también habían acordado en 1890 que era inútil tratar de controlar la competencia mediante cárteles, aun cuando una comisión del gobierno apoyara y regulara a estas asociaciones. Después de 1893 pocos ferroviarios consideraban que la reglamentación gubernamental fuera más práctica que la construcción de sistemas para el control de la competencia. ${ }^{\text {is }}$

\footnotetext{
${ }^{14}$ Martin, "Troubled", 1974; Chandler, Visible, 1977; Purcell, "Ideas", 1967.

${ }^{15}$ Chandler, Visible, 1977, p. 175.
}

\footnotetext{
${ }^{10}$ Martin, "Troubled", 1974, pp. 339-371.

${ }^{11}$ Chandler, Visible, 1977, p. 172.

${ }^{12}$ Ibid., p. 173.

${ }^{13}$ Kolko, Railroads, 1970.
} 
El historiador ferroviario Albro Martin concuerda con que la formación de sistemas logró su objetivo principal y añade que

la regulación, progresista después de 1908 , originalmente era punitiva, de aplicación represiva y de efectos destructivos en cuanto a la posibilidad de que los ferrocarriles obtuvieran las ganancias necesarias para mejorar y para su expansión. ${ }^{16}$

Partiendo de esta perspectiva, la Ley Elkins (1903), la Ley Hepburn (1906) y especialmente la Ley Mann-Elkins (1910) reforzaron muy eficazmente los poderes de la $\mathrm{CCI}$ en cuanto concernía al establecimiento de tarifas.

A estas alturas, los ferrocarriles ya habían controlado de hecho la competencia mediante la construcción de los sistemas mayores y la formación de "comunidades de interés". Ni siquiera cuando Roosevelt disolvió la Compañía de Seguros del Norte (1904) se afectaron los sistemas ya consolidados. Estaban hechos para funcionar bajo la reglamentación del gobierno mediante una comisión independiente. En conclusión, la historiografía demuestra que el proceso de interacción entre el gobierno y la industria ferroviaria llevó en última instancia a la consolidación de los sistemas ferroviarios privados y a que operaran bajo reglamentación gubernamental.

¿Qué pasó en el caso de México? La historiografia mexicana ha fallado en responder a esta pregunta, misma que considero clave para poder entender nuestro proceso de consolidación, con propiedad mayoritaria del gobierno, de los últimos años del porfiriato.

En pocas palabras, entiendo la necesidad del gobierno mexicano de poseer

\footnotetext{
${ }^{16}$ Martin, "Troubled", 1974.
}

los ferrocarriles (que culminaría con la formación de Ferrocarriles Nacionales de México) como el resultado de un proceso histórico de interacción entre el gobierno y la industria ferroviaria a través del tiempo. Por tanto, para explicar adecuadamente la política ferrocarrilera de esta época, es necesario analizar el impacto de las diferentes formas en que el gobierno intervino en el desarrollo de la industria ferroviaria, y cómo a su vez afectó al gobiemo la evolución de esta industria.

Utilizando este punto de vista analitico es posible identificar varios aspectos críticos que no se han considerado en otros estudios de la consolidación. ¿Cómo respondieron los ferrocarriles mexicanos (cuando eran propiedad privada extranjera) a los problemas de la industria, por ejemplo, a los altos costos fijos, a la competencia ruinosa, etc.? ¿Existían en verdad en la industria mexicana poderosas presiones competitivas que orillaran a la consolidación privada? Si así fue, ¿Cómo enfrentaron los ferrocarriles estas presiones hasta 1898? ¿Cómo respondió el gobierno mexicano a las presiones económicas y políticas que surgían de los problemas y de la actitud de la industria ante ellos? ¿Cómo actuó el gobierno antes de optar por la estrategia de controlar la compra de acciones en 1902? ¿Qué efectos tuvo la política del gobierno en la organización y eldesarrollo de la industria ferrocarrilera, antes y después de su consolidación?

Lógicamente, al estudiar estas preguntas, es indispensable tomar en consideración el entorno histórico de México, su geografia, nivel de desarrolloeconómico, mercado nacional e internacional, momento de introducción de los ferrocarriles, sistema político y legal, estructura social, etc. Es natural pensar que estos factores incidieron significativamente, 
tanto en los problemas de la industria como en la percepción que de estos problemas tuvieron los diferentes actores involucrados.

\section{UNA REINTERPRETACIÓN TENTATIVA}

Al comenzar 1890, cuando las principales vías férreas mexicanas fueron finalmente terminadas, ya empezaban a surgir problemas propios de una industria ferrocarrilera en funcionamiento. Para los ferrocarriles mexicanos, la década de 1890 fue un periodo difícil en el cual se enfrentaron a la competencia para atraer el flujo de tráfico.

Existe el consenso de que el Ferrocarril Mexicano (ciudad de México-Veracruz), que conservó el monopolio del transporte vía ferrocarril hasta la mitad de la década de 1880, cobraba "tarifas escandalosamente altas", como lo co- mentó un observador británico. ${ }^{17}$ Entre 1873 y 1890 , los funcionarios del gobierno y los "grupos mexicanos de negocios" pensaban que la competencia era la mejor forma de resolver el problema de las tarifas excesivamente altas. Sin duda alguna, la necesidad de acabar con el monopolio y de promover la competencia eran motivos suficientes para construir vías férreas al inicio del porfiriato. ${ }^{18}$

La terminación de las líneas rivales norte-sur y del Golfo, Ferrocarril Central: México-El Paso (1884) y AguascalientesTampico (1890); Ferrocarril Nacional: México-Laredo (1880); Ferrocarril Interoceánico: México-Veracruz (1891), dio como resultado una intensa competencia y tarifas muy bajas, sobre todo para el tráfico internacional, tal y como lo

${ }^{17}$ Schmidt, Social, 1974, p. 174.

${ }^{18}$ Ibid; ; Parlee, Porfirio, 1981, pp. 11-99.

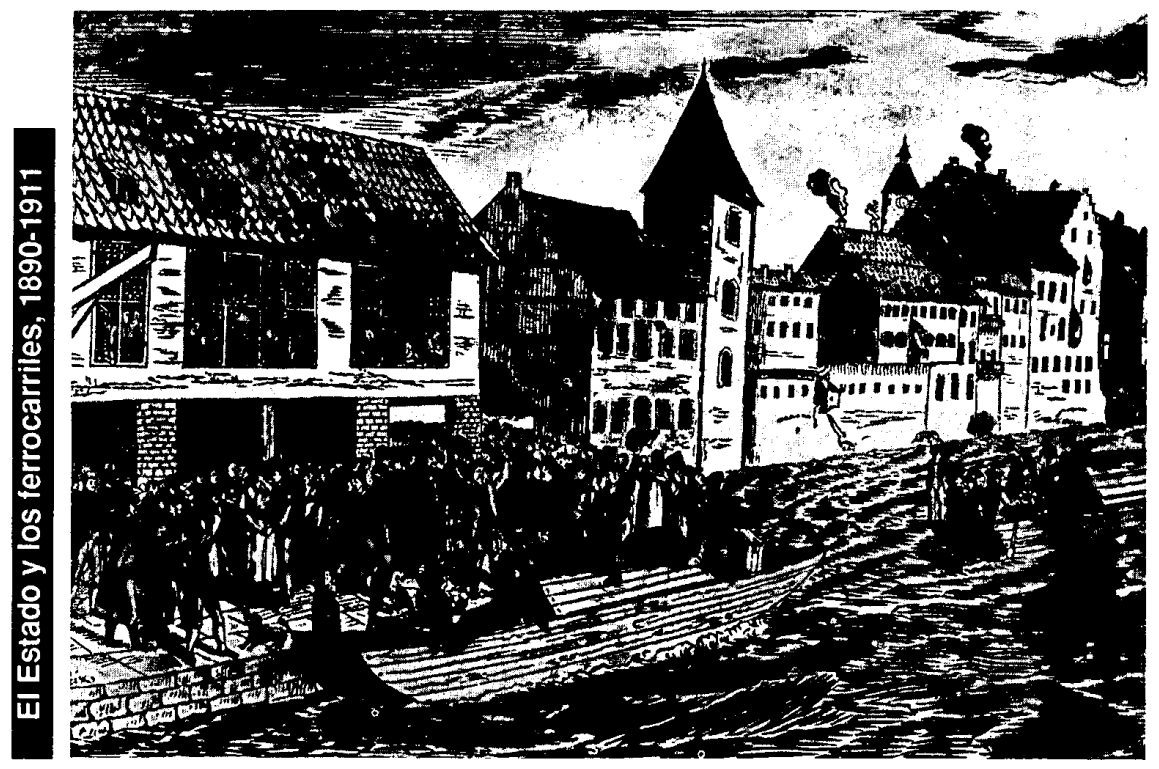


deseaban muchos de los fletadores y funcionarios mexicanos. A mediados de la đécada de 1880, el Central Mexicano inició una política de tarifas preferenciales y reducción en los precios del flete si la carga era muy grande, con el objeto de ganarle tráfico de importación al Ferrocarril Mexicano. Esto culminó con una encarnizada guerra de precios que involucró a las cuatro compañías más importantes, entre 1891 y $1892 .{ }^{19}$

En junio de 1892, para atraer carga de México a Tampico y a El Paso, el Ferrocarril Central bajó sus tarifas a un cuarto de los precios que daba el Ferrocarril Mexicano de Veracruz a los mismos destinos. "Se dio lo inevitable: en dos meses los ferrocarriles Nacional e Interoceánico ajustaban sus precios cada día para tratar de mantenerse a la par que sus competidores." 20

Para el Ferrocarril Mexicano las presiones eran particularmente fuertes. Continuamente debían enfrentar costos enormes. Aun cuando los subsidios del gobierno le significaban un cierto alivio, los gastos generales eran inmensos por los altos costos de construcción (debido esto, sobre todo, a la topografia del país), sobrecapitalización y más importante aún, la caída de la moneda mexicana de plata.

Las industrias ferroviarias del porfiriato tenían que pagar con oro los gastos fijos y de operación, mientras que sus ganancias las percibían en plata en proceso de devaluación. Tenían que importar las vías de acero, las máquinas, el material rodante y casi todo el carbón.

Como Coatsworth explica, los enlaces ferroviarios tenían, durante el porfiriato, serias fugas hacia las naciones industria-

${ }^{19}$ La Semana Mercantil, 1890-1892; The Mexican Financier, 1890-1892; Parlee, Porfirio, 1981, p. 120; Tischendorf, Great, 1961, pp. 52-53.

${ }^{20}$ Tischendorf, Great, 1961, p. 53. lizadas. ${ }^{21}$ Peor aún, la dependencia mexicana de la inversión extranjera obligaba a los ferrocarriles a remitirle sus dividendos y pago de intereses en moneda valuada en oro. Al enfrentar problemas de escasez de trabajadores capacitados, se comprometían a pagar en oro a sus empleados norteamericanos y europeos (incluyendo gerentes de nivel alto y medio, ingenieros, conductores, etc.), creando así un sistema doble de pago que prácticamente discriminaba a los mexicanos.

No es sorprendente que varias fuentes culpen a muchos ferrocarrileros del porfiriato, así como a varios funcionarios del gobierno, del "problema ferrocarrilero mexicano". ${ }^{22}$ Varios historiadoresseñalan correctamente la importancia de la situación de la plata, pero ninguno la analiza respecto a sus efectos agravantes de los problemas estructurales de la industria ferrocarrilera mexicana. ${ }^{23}$ En México se acentuaron las dificultades de la competencia oligopólica por los costos mayores a los normales.

Hubo otros problemas en el desarrollo de los ferrocarriles mexicanos que aumentaron la presión por detener la guerra de precios. Al igual que en algunas regiones del oeste de Estados Unidos, se construyeron algunas líneas paralelas a zonas donde se debía establecer gradualmente un desarrollo eco-

${ }^{21}$ Coatsworth, Impacto, 1984.

${ }^{22}$ Estas quejas se pueden encontrar en innumerables referencias, para citar unas cuantas: Annual Report of the Mexican Central Railway Co. 1890-1900, Centro de Estudios de Historia de México (CONDUMEX), miscelánea de ferrocarriles; Mexican Herald, 21 de febrero de 1899, 12 de junio de 1899,9 de enero de 1903, 1 de junio de 1903 y 28 de septiembre de 1903; Mexican financier, 31 de enero de 1891 y 1 de agosto de 1891 .

${ }^{23}$ Calderón, "Ferrocarriles", 1965; Coatsworth, Impacto, 1984; Parlee, Porfirio, 1981; Schmidt, "Social", 1973; Tischendorf, Great, 1961; Ortiz Hernán, Ferrocarriles, 1987. 
nómico junto a la introducción del transporte de carga. Resulta entonces que varios de los problemas ferroviarios en México -rebajas excesivas, discriminación en favor del transporte de larga distancia en contra de aquél de trechos cortos y competencia destructiva- eran síntomas de una red ferroviaria construida en un país nuevo, cuya capacidad era superior a la demanda efectiva de tráfico.

La guerra de tarifas de 1891 a 1892 coincidió con una de las cosechas más pobres del porfiriato y con la caída del precio de la plata al punto más bajo desde que Díaz había subido al poder en 1876. ${ }^{24}$ Exhaustos, los ferrocarriles Británicos, Mexicano e Interoceánico celebraron una conferencia de pazen Londres a mediados de agosto, con el fin de llegar a un acuerdo de cooperación. Los Ferrocarriles Central y Nacional, propiedad de norteamericanos, estaban dispuestos a participar en la junta, dado que, durante la guerra de precios, sus pérdidas habían sido más altas de lo que podían aceptar sus ejecutivos. Si bien las cuatro líneas obtenían del tráfico local la mayor parte de sus ganancias, todas reportaron pérdidas serias causadas por el transporte de enormes cargas de importación a "precios de sacrificio". ${ }^{25}$

En Londres, las compañías accedieron a formar un pool con el producto de las importaciones europeas destinadas a puntos competitivos en México (ciudad de México, San Luis Potosí, Pachuca). El acuerdo incluía el establecimiento de tarifas uniformes (con un aumento aproximadamente del $100 \%$ sobre los "precios de sacrificio"), la formación de un pool con los ingresos mayores y la asignación de un porcentaje fijo para cada compañía.

${ }^{24}$ La Semana Mercantil, 23 de julio de 1902; Tischendorf, Great, 1961, p. 53.

${ }^{25}$ Financial News, 11 de agosto de 1892.
Por cada tonelada de carga, ocho pesos se destinaban al ferrocarril que lo transportaba; $45 \%$ del sobrante iban al Mexicano, $20 \%$ al Central y $12 \%$ al Nacional. No hicieron más arreglos respecto a otras clases de tráfico, pero coincidieron en que las importaciones de Estados Unidos a la capital o a sus alrededores, provenientes de Veracruz, Tampico, El Paso y Laredo, serían cobradas a precios fijos, dependiendo del artículo involucrado.

Además, las compañías formaron la Asociación Mexicana de Tráfico. Conesto, los gerentes generales de los cuatro ferrocarriles se convirtieron en ejecutivos de la asociación, con poder para decidir todo asunto relacionado con los acuerdos sobre tráfico, y con jurisdicción sobre cualquier carguero que viniera a México con intenciones de competir. La asociación tenía también el poder de fijar multas por abusos, como clasificaciones falsas, rebajas secretas, menor emisión de boletos, boletos falsos y pago de comisiones.

Hubo otros acuerdos fuera de la jurisdicción directa de la asociación. Los ferrocarriles Mexicano e Interoceánico aceptaron fijar las tarifas y formar un $p o o l$ con lo obtenido del tráfico nacional cuando se llegara a un punto de competencia. ${ }^{26}$

Numerosas compañías mexicanas de fletadores, guiadas por la Cámara de Comercio de la ciudad de México, se opusieron inmediatamente a los acuerdos de cooperación y trataron de que el gobierno actuara en su contra. Presionaron a la recién formada Secretaría de Comunicaciones y Obras Públicas (SCOP) para

${ }^{26}$ Tischendorf, Great, 1961, p. 53; Coatsworth, Impacto, 1984, Archivo General de la Nación (AGN), Archivo Histórico de la Secretaría de Comunicaciones y Transportes (AHSCT), Ferrocarriles, carpetas 9/ 61-1, 9/65-2, 9/65-3, 9/65-7; Annual Report of the Mexican Central Railway, 1895, CONDUMEX, miscelánea 9, folleto 4; La Semana Mercantil, 19 de septiembre de 1892 . 
que declarara ilegales todos los acuerdos declarando "que todas las cargas pagadas a los nuevos precios excediendo los anteriores serán devueltas a los importadores y las nuevas tarifas se declararán nulas e inválidas". ${ }^{27}$

Los fletadores basaban

sus peticiones en la anticonstitucionalidad de los monopolios, y en el error de las compañias por no dar aviso con 30 dias de anticipación, como lo requiere la ley, en el caso de un aumento en las tarifas. ${ }^{28}$

La scop y el presidente Díaz estuvieron completamente de acuerdo con los fletadores y "notificaron a los ferroviarios que el gobierno actuaría en su contra si no restituían las antiguas tarifas". ${ }^{29}$ Sin embargo, las compañías no se dejaron intimidar y contestaron que las nuevas tarifas estaban perfectamente en regla dentro de los precios máximos autorizados en la concesión, y continuaron con ellas. El cónsul británico Bland informó a la Oficina de Asuntos Exteriores que a pesar de que Díaz y su gobierno permitieron de mala gana que se realizaran los cambios, el presidente, en privado, seguía manifestando su desacuerdo con la "manía por los pactos que ha hecho presa de los ferrocarriles". ${ }^{30}$

Desde su inicio en 1891, la scop había logrado cierto éxito en sus intentos por profundizar la inspección gubernamental en las operaciones financieras de los ferrocarriles. Pero como lo demuestra su incapacidad para evitar la formación de pools, la scop no actuó muy eficientemente en los asuntos concernientes al tráfico y a sus tarifas. De acuerdo con los

${ }^{27}$ La Semana Mercantil, 19 de septiembre de 1892; The Railroad Gazette, 30 de diciembre de 1892.

${ }^{28}$ Ibid.

29 Ibid.

30 Tischendorf, Great, 1961, pp. 53-54. directores del Ferrocarril Nacional, la SCOP no estaba ejerciendo plenamente sus derechos para prevenir que las compañías cayeran en una ruina financiera. ${ }^{31}$

Los reportes de las compañías revelan que el acuerdo para la formación del pool brindó cierto desahogo a las finanzas de la industria ferrocarrilera. El efecto positivo se dio tanto en los ingresos como en la devolución de la confianza a los inversionistas, según se pudo observar en los valores de los principales mercados financieros de Estados Unidos y Europa. ${ }^{32}$

A pesar de que resistieron la oposición de los fletadores mexicanos y del gobierno, los acuerdos resultaron frágiles y duraron tan sólo hasta 1895. El Ferrocarril Mexicano consideró que la distribución fijada era injusta, dado que la carga que transportaba no guardaba proporción con lo que recibía de ganancias. El Central y el Nacional acusaron a sus competidores británicos de violar constantemente las tarifas fijas establecidas para las importaciones de Estados Unidos. Cuando las líneas del Golfo sugirieron un reajuste del pooleuropeo y la formación de otro para el tráfico de Estados Unidos, el Central, seguido por el Nacional, se retiró de los acuerdos.

A continuación se dio una intensa guerra de precios. Comoera de esperarse, las consecuencias en 1895 y 1896 fueron una caída a pique de las tarifas del tráfico internacional y un serio declive en las ganancias de todas las compañías involucradas. Quien salió victorioso en este problema fue el Ferrocarril Central, ya que era el menos dependiente del tráfico internacional, y por consiguiențe, la compañía mejor preparada para resistir el desmoronamiento de las tarifas de importación.

\footnotetext{
${ }^{31}$ Parlee, Porfirio, 1981 , p. 120.
}

${ }^{32}$ Mexican Financier, 1893-1894. 


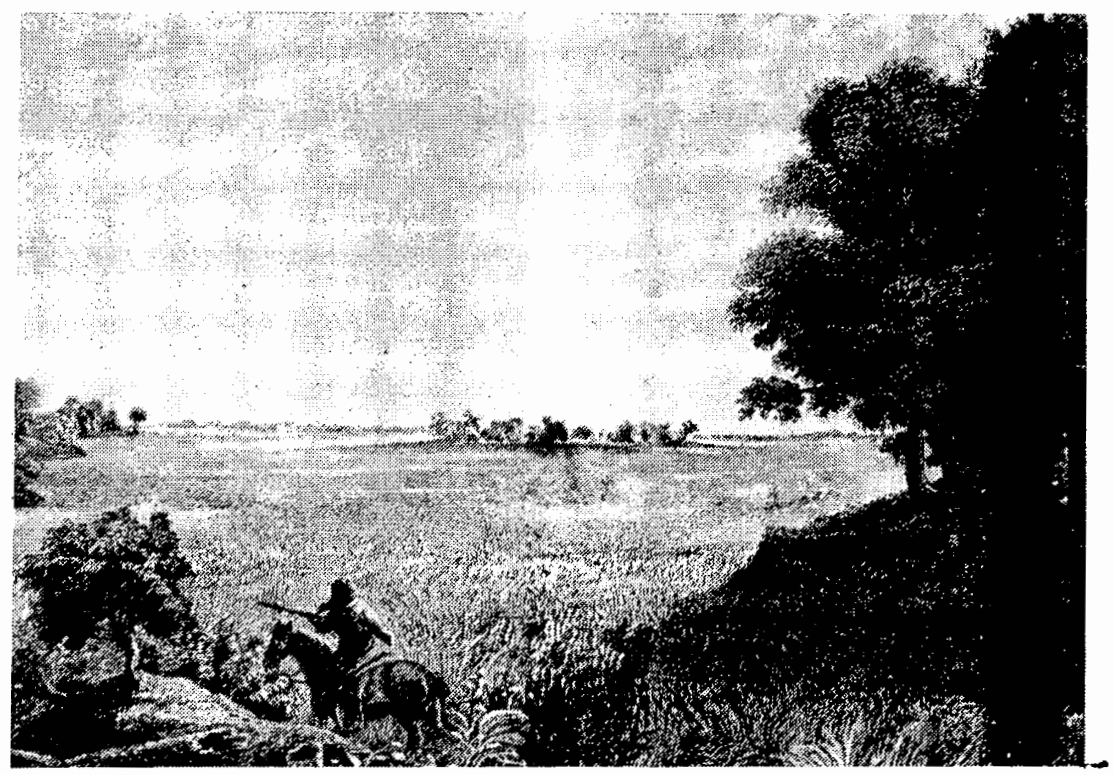

Finalmente, "en verdad cansados" de la guerra de precios y "sinceramente deseosos de paz", los ferrocarriles se reunieron en una nueva Asociación Mexicana de Tráfico, y a fines de octubre de 1896 firmaron un acuerdo revisado para mancomunar las ganancias del tráfico europeo y cobrar tarifas similares en la mercancía que llegara a México y a Estados Unidos. ${ }^{33}$ Como resultado de la revisión, se aumentaron las tarifas para el tráfico de importación, aunque los precios del transporte maritimo-terrestre se mantuvieran más bajos que los del transporte terrestre.

Este ajuste se reflejó en la victoria del Central, ya que tenía salidas por tierra a través de El Paso y por mar en el Golfo de

33 Tischendorf, Great, 1961, pp. 54-55; AGN, AHSCT, Ferrocarriles, carpetas 9/60-1, 9/65-7; Mexican Financier, 6-13 de junio de 1896.
México (Tampico). Las compañías se comprometieron a esforzarse para establecer en un futuro próximo un pool para la carga de importación de Estados Unidos, con base en las estadísticas del tráfico de esta carga que calcularía la asociación. La extensión del acuerdo estaría sujeta a una nueva revisión de los términos cada tres años, y los miembros que quisieran retirarse debían notificarlo con seis meses de anticipación o bien pagar fuertes multas. ${ }^{34}$

Los acuerdos de 1896 se mantuvieron sin cambios, cuando menos en la forma, durante el tiempo que restaba de la década. Esto era relativamente mucho tiempo en comparación con la experiencia que

${ }^{34}$ Mexican Financier, 13 de junio de 1896; CONDUMEX, miscelánea de ferrocarriles, folletos 24, Annual Report of the Mexican Central Railway, 1895-1897. 
tuvo Estados Unidos con acuerdos parecidos. Pero otra vez el acuerdo de 18961899 resultó ser una solución poco confiable y más bien limitada en su capacidad para resolver el problema de la competencia entre los ferrocarrileros.

En la práctica, las compañías encontraban dificil el cooperar en las cargas de importación. El Ferrocarril Mexicano seguía resintiendo el tener que "subsidiar a las otras compañías". ${ }^{35}$ Su presidente opinaba que, según los términos establecidos en 1896 , su compañía "contribuía a formar el poolmucho más que lo que de él recibía". ${ }^{36}$

Al Ferrocarril Nacional, que carecía de una conexión con el Golfo, le convenían poco los precios menores que ofrecía el transporte marítimo en comparación con el terrestre. El presidente de la compañía se quejó en 1897, diciendo que:

...el acuerdo ha resultado muy poco satisfactorio para el manejo de esta compañía, por la razón de que se permite a nuestros asociados y a la vez competidores en el tráfico, transportar cargas de puntos comunes de Estados Unidos a puntos comunes de México a un menor precio del que nosotros podemos ofrecer, por el hecho de que nosotros carecemos de conexiones marítimas con Estados Unidos, que es de donde viene la mayor parte de la carga [...] los beneficios esperados por haber fijado tarifas más altas en el acuerdo, se neutralizan por la pérdida de tonelaje que sufrimos en favor de los otros ferrocarriles. ${ }^{37}$

Varias organizaciones de fletadores siguieron manifestando su firme oposición a los acuerdos, como parte de su descontento general con la estructura de

35 AGN,AHSCT, Ferrocarriles, carpetas 9/65-7. También se pueden ver los reportes semianuales publicados en el Soutb American Joumal.

${ }^{36} \mathrm{Ibid}$.

${ }^{37}$ AGN,AHSCT, Ferrocarriles, carpetas 10/2318-1. las tarifas en México. ${ }^{38}$ Como resultado de los acuerdos, las tarifas de importación para destinos competitivos, comprendidos en la mayor parte del tráfico internacional, se habían estabilizado y aumentado a pesar del rompimiento temporal de 1895-1896.

Con todo, en parte porque las tarifas de exportación permanecían fuera de los acuerdos, el ingreso por concepto de carga internacional era una entrada que iba disminuyendo en el total de las ganancias obtenidas durante la década de 1890.

La otra razón para esto era que el tráfico nacional, con flujo a sitios poco competitivos, comenzó a soportar costos de transporte mayores que el tráfico internacional. Parlee sugiere que

de 1892 a 1898 el tonelaje de importación y exportación del Central aumentó $181 \%$, mientras que los ingresos por concepto de carga aumentaron tan sólo $55 \%$. Por otro lado, el tonelaje de carga doméstica creció únicamente en $8 \%, y$ los ingresos por concepto de esta fuente aumentaron $98 \% .{ }^{39}$

Parecería como si los ferrocarriles trataran de compensar sus pérdidas en el tráfico internacional cobrando tarifas excesivas en el poco competitivo transporte de carga doméstica a través de distancias cortas.

Pero no hay evidencia que sugiera que el gobierno respondiera en realidad a las peticiones de los fletadores. Como se señaló previamente, nunca cumplió su prohibición inicial de los acuerdos. Más bien, a diferencia de 1892, en 1896 no hizo nada para interferir en la formación de la segunda Asociación Mexicana

\footnotetext{
${ }^{38}$ Varios artículos de La SemanaMercantil, 18951900, y de el Boletín de la Sociedad Agrícola Mexicana, 1896-1899.

${ }^{39}$ Parlee, Porfirio, 1981, p. 125.
} 
de Tráfico. Es cierto, sin embargo, que, por lo menos hasta final del siglo, no había dado ningún apoyolegal ni jurídico para el mantenimiento de los pools privados y de los acuerdos sobre tarifas fijas.

Con todo, se puede observar que la actitud del gobierno hacia las compañías ferroviarias era cada vez más flexible y tolerante. A lo largo de la década, la queja común de todas las compañías fue la devaluación de la moneda mexicana de plata. No se podía compensaresta pérdida ni con la reducción de la competencia mediante la Asociación Mexicana de Tráfico ni con el considerable y continuo aumento de tráfico. Para resolver este problema, los ferrocarriles solicitaban constantemente a las autoridades la aprobación de un aumento general en las tarifas. A pesar de la fuerte oposición de las organizaciones de fletadores, el gobierno, tras resistirse algunos años, finalmente consintió en aprobar el aumento en 1898. En este año, la scop permitió una reclasificación de la carga aumentando a doce las tres clases existentes, lo que se utilizó para incrementar el nivel promedio de las tarifas, reordenando los artículos según la nueva clasificación. ${ }^{40}$ En conclusión, aunque el gobierno mexicano ejerció cierto control en la industria y en teoría se oponía a cualquier actividad monopólica, la realidad es que, cuando menos hasta el final de la década de 1890 , el principio de la política porfiriana consistía en proteger los intereses extranjeros invertidos en los ferrocarriles mexicanos.

Ésta era la situación de los ferrocarriles mexicanos cuando Limantour elaboró su primer programa para el desarrollo ferroviario y se hizo cargo de los principales aspectos de la política ferroviaria en 1898.

${ }^{40}$ Ibid.
Desde su nombramiento como secretario de Hacienda en 1893, Limantour se dedicó a aliviar la severa crisis fiscal y financiera del gobierno. En el inicio se percató del grave problema que representaban los ferrocarriles debido a la inmensa carga que suponían para la administración los numerosos y a veces excesivos subsidios con que los favorecía. Aparentemente, en sus primeros años dentro del gobierno, no le preocuparon otras facetas de la industria ferroviaria, como por ejemplo, el problema de las tarifas y los acuerdos de cooperación para controlar la competencia.

Durante casi toda la década de 1890 , Limantour se dedicó a recortar los subsidios gubernamentales a los ferrocarriles como parte de su esfuerzo por reducir la deuda externa e interna. Esto culminó en la formulación de su plan de 1898 , basado en el principio de que el gobierno daría concesiones y subsidioúnicamente a siete de las líneas principales necesarias para completar la red ferroviaria. ${ }^{41}$ Este programa se incorporó a la nueva ley de Ferrocarriles presentada en 1898 y aceptada por el Congreso el 29 de abril de $1899 .{ }^{42}$

La consideración prioritaria del secretario en los acuerdos ferroviarios era indudablemente el aspecto financiero de los subsidios. Esta preocupación lo hizo interesarse en otros aspectos del problema de los ferrocarriles mexicanos. Así se dio cuenta de que la carencia de un plan de construcción racional y la asignación arbitraria de subsidios entre 1880 y 1890 eran en gran parte responsables de las dificultades económicas de algunas lineas y de la existencia de una "competencia destructiva e innecesaria". ${ }^{43}$

\footnotetext{
4 El programa de 1898 se encuentra en SHCP, Memoria, 1899.

${ }^{42}$ SCOP, Ley, 1910.

${ }^{43} \mathrm{SHCP}$, Memoria, 1899.
}

\section{9}

1 


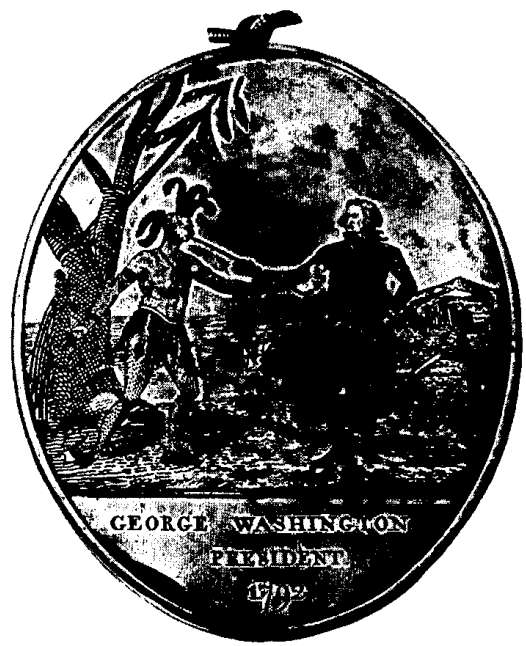

Definitivamente el plan de 1898 fue un intento de tratar el asunto de los subsidios básicamente como un problema fiscal, pero también fue concebido como una estrategia para controlar la competencia en las rutas en las que el tráfico únicamente podía sostener a una línea.

Los planes tuvieron éxito en cuanto a la prevención de la construcción de nuevas líneas competitivas; ${ }^{44}$ pero cuando éstas ya existian era necesaria una solución diferente, como se demostró en los esfuerzos de cooperación de las compañías en la década de 1890.

El programa de 1898 de Limantour no contiene ninguna especificación en cuanto a tarifas, poolsy otros acuerdos de cooperación. Sin embargo, estos aspectos se estudiaron sistemáticamente en la 220. nueva legislación de 1899 , de la cual él era el principal creador. ${ }^{45}$

En los últimos años de la década, el gobierno mexicano (en contra de la mayoría de las organizaciones de fletadores) ya no creía en la errónea noción de que era deseable la libre competencia. En conclusión, conforme al artículo 114 de la ley de 1899 , el gobierno mexicano aceptó formalmente una solución cooperativa para la competencia ruinosa, legalizando los pools y haciendo oficiales los acuerdos sobre tarifas, siempre que contaran con una adecuada supervisión.

Cualquier cambio en las tarifas aún debía ser aprobado por la SCOP antes de ser puesto en práctica. Además, las tarifas competitivas tenían que fijarse de acuerdo con los costos de transporte por la vía más corta y directa.

Para proteger a los fletadores nacionales, la ley prohibió las rebajas secretas y cualquier forma de discriminación, además de puntualizar que las compañías, en condiciones y circunstancias similares, no podían cobrar más por un transporte corto que por uno de mayor distancia sobre la misma vía y con igual dirección. Sin embargo, aceptaba algunas situaciones excepcionales en las que los costos más bajos por tonelada/milla y la competencia justificaban costos unitarios menores en las distancias más largas. Finalmente, se dio protección al tráfico nacional estipulando que quedaban prohibidas las tarifas reducidas para los artículos extranjeros similares que hicieran el mismo recorrido en territorio mexicano. ${ }^{46}$

Si bien tanto los fletadores ${ }^{47}$ como los cargadores aceptaron la promulgación

\footnotetext{
4s SCOP, Ley, 1910.

${ }^{46}$ Ibid.

${ }^{47}$ La Semana Mercantil, 15 de enero de 1900.
} 
de la ley como un paso para solucionar los problemas de la industria, los ferrocarrileros la recibieron con mayor entusiasmo. Por consiguiente, cuandoen 1900 el vicepresidente del Ferrocarril Central Mexicano regresó de Nueva York de una reunión de la Asociación Mexicana de Tráfico con sus colegas norteamericanos, comentó:

Habia, por supuesto, mucho interés en el asunto, y los ferrocarrileros de Estados Unidos hicieron comentarios halagüeños al respecto. Al igual que todos nosotros (administradores ferrocarrileros en México) piensan que es muy positiva y nos traerá muchas ventajas. ${ }^{48}$

La evidencia claramente demuestra que el gobiemo mexicano, al final del siglo, estaba decidido a solucionar el problema de la competencia permitiendo a las compañias ferroviarias cooperar bajo su supervisión. Al promulgarse la ley de 1899, ta Asociación Mexicana de Tráfico, los pools y todos los demás acuerdos sobre tarifas fijas quedaban legalmente aprobados y sancionados oficialmente.

A pesar de los problemas que generaron los arreglos de cooperación de 1896 , a fines de 1899 Ios ferrocarriles mexicanos firmaron nuevos acuerdos. Las líneas de Veracruz, en especial el Ferrocarril Mexicano, hicieron un mejor trato respecto al pool de la carga europea. $\mathrm{El}$ ingreso de ganancias brutas aumentó de $69 \%$ a $79.4 \%$ y disminuyó proporcionalmente el porcentaje destinado al Ferrocarril Central y al Nacional.

Las compañías no pudieron llegar a un acuerdo en cuanto al pool para las importaciones de Estados Unidos, como se habían comprometido en 1896. Sin embargo, en respuesta a las quejas del

\footnotetext{
${ }^{48}$ Mexican Herald, 21 de enero de 1900.
}

Ferrocarril Nacional, hicieron un nuevo arreglo sobre las tarifas fijas, que permitia una reducción de las tarifas terrestres por tonelada/milla, pero que mantenía el transporte marítimo, para los mercados interiores más importantes, a un precio total menor. ${ }^{49}$ Así, el presidente del Ferrocarril Nacional explicó en 1899 que "la modificación hecha en el reajuste de 1899 es únicamente eso, una modificación, no una solución al problema; la verdadera justicia e igualdad no se lograrán hasta que todas las líneas cobren exactamente igual por transportar la misma cantidad y calidad de carga entre los mismos puntos"..$^{50}$

La Asociación de Comerciantes de la ciudad de México, Tampico y Veracruz reclamó porque la autorización a la reducción de las tarifas dañaría sus intereses desviando el tráfico de los puertos del Golfo hacia Nueva Orleans y Galveston. ${ }^{51}$

Una vez más, sin hacer caso de los fletadores, el gobierno mexicano aprobó, con la nueva ley, los ajustes de 1899. En forma similar, a pesar de la violenta oposición de los hacendados pulqueros del centro de México, una vez que revisó los efectos de los acuerdos de cooperación en los ferrocarrileros, los productores y los consumidores, el gobierno sancionó la formación de un pool entre los Ferrocarriles Mexicano e Interoceánico y las líneas Hidalgo y Noreste, que elevaba las tarifas para los envíos de esta bebida de consumo popular.

Cuando a principios de 1900 las líneas del Ferrocarril Mexicano y del Interoceánico decidieron aumentar sus tarifas para el tráfico de exportación, las cámaras de Comercio de Veracruz y de la ciudad de México, así como la Asocia-

\footnotetext{
49 Tischendorf, Great, 1961, p. 55.

${ }^{\text {so }} \mathrm{AGN}, \mathrm{AHSCT}$, Ferrocarriles, carpeta 10/3176-1.

${ }^{51}$ La Semana Mercantil, 27 de enero de 1902.
} 
ción de Sociedades Agrícolas (constituida sobre todo por hacendados), pidieron al gobierno que les diera protección. En su esfuerzo por lograr una reglamentación adecuada, estas organizaciones de fletadores mexicanos habían elaborado un reporte detallado de las deficiencias básicas generadas en los cambios de los femocarriles de México. Brevemente, los comerciantes y los terratenientes influyentes argumentaron que, mientras el tráfico y los réditos de las compañías aumentaban considerablemente, las tarifas no habían descendido proporcionalmente, en especial las cobradas a las enormes cargas de artículos para el mercado interno, como maíz, frijol y otros productos agrícolas. $^{52}$

Como respuesta a esto, el gobierno mexicano logró convencer al Ferrocarril Mexicano y al Interoceánico de que el incremento era excesivo. Además, decidió crear una Comisión Revisora de Tarifas destinada a mejorar la aplicación de las cláusulas de la nueva ley al respecto.

La formación de esta comisión es prueba de que el gobierno permitía los pools con la condición de que se controlaran adecuadamente las tarifas. Desafortunadamente, se conoce poco acerca de la eficacia de la comisión como instrumento para dar solución al problema de la libre competencia y para aplicar tarifas justas y razonables..$^{53}$

52 La Semana Mercantil, 1900-1901.

${ }^{33}$ Coatsworth arguye que la disminución en los ingresos de los ferrocarriles por tonelada/milla entre 1902-1910 puede atribuirse en parte a una comisión dominada por los fletadores. Sin embargo, después señala que mientras que las tarifas para casi todo tipo de tráfico aumentaron, para 1890 ya habia comenzado la disminución de ingresos por tonelada/milla, y continuó durante el resto del porfiriato.

Coatsworth trata de explicar esta contradicción con dos argumentos: primero, que la paradoja
Mi opinión es que la competencia siguió siendo problema en el México del porfiriato, a pesar de los esfuerzos de las compañías y del gobierno para evitarlo. No he encontrado todavía evidencia de que hayan existido acuerdos formales para la exportación, que era la categoría principal en el tráfico competitivo. El establecimiento de la Asociación Mexicana de Tráfico y la supervivencia (más bien precaria) de los poolsy los acuerdos sobre tarifas fijas brindaron un control

entre la disminución general de ingresos yel alza en las tarifas se explica en mucho por la creciente proporción de tráfico de exportación (sobre todo de minerales) que estaba sujeta a tarifas mucho menores que otros tipos de carga. Segundo, que la carga doméstica y de importación era transportada a un precio mayor debido al apoyo que el gobierno dio a la formación de pools, y porque el tráfico local que se transportaba era de menor volumen y recorría distancias menores. En tercer lugar, afirma que la estructura de las tarifas estaba determinada por la influencia de los grandes productores de artículos de exportación que controlaban la política ferrocarrilera del porfiriato.

Sugiere incluso que el gobierno seleccionaba representantes del sector exportador para que aplicaran su criterio en la Comisión Revisora de Tarifas. Para mí, estos argumentos tienen ciertos inconvenientes. A pesar de que el tráfico de exportación era sin duda el que pagaba la menor tarifa, es un error atribuir esto a las preferencias políticas y de desarrollo del gobierno.

Para empezar, también existían razones importantes de costo y del valor del servicio para cobrar estas tarifas. Los minerales constituían el principal artículo de exportación. Aun si el mineral tenía un valor unitario superior al de digamos el maíz, estaba dentro de una clasificación inferior y no podía soportar costos altos de transporte. Además, los minerales mexicanos generalmente implicaban costos bajos de transporte por sus características de carga, lo poco factible que era su daño o pérdida, su enorme volumen y lo regular de su movimiento (hasta $45 \%$ aproximadamente de la carga del $\mathrm{Na}$ cional y del Central en la última década del porfiriato), el tipo de equipo requerido, y finalmente porque no necesitaban de servicios caros como refrigeración, protección del frío, colocación especial, etcétera. 
muy limitado a la competencia en las importaciones y, en menor proporción, a algunos artículos nacionales que eran motivo de tráfico competitivo. Parece que nunca se alcanzó una de las metas perseguidas tanto en la ley de 1899 como en la creación de la Comisión Revisora de Tarifas, que posiblemente perseguía lo-

El examen de las Memorias de la Comisión Revisora de Tarifas (1906, 1908, 1909 y 1911) revela que la combinación de estos criterios de costo y valor del servicio, con ciertas consideraciones sobre el desarrollo (como la promoción de exportaciones y el proteccionismo industrial), fue la guia usada en las deliberaciones de la Comisión.

En cualquier caso, Coatsworth no provee ninguna evidencia convincente que apoye su hipótesis de que los miembros de la Comisión eran representantes de los exportadores. De hecho, he encontrado que, cuando menos, algunos de los cinco miembros de la Comisión tenían negocios ligados a los ferrocarriles. Este es el caso, por ejemplo, de Emilio Velasco, que había trabajado grar una solución mediante la operación de un cártel sujeto a reglamentación estatal.

Incluso con la legalización de los pools, las cuatro lineas principales nunca pudieron lograr nada más que un frágil acuerdo sobre la fijación de tarifas para las importaciones de Estados Unidos. A pesar

como consejero legal en algunas de las compañías extranjeras más importantes. La verdad es que aún nos queda mucho por saber acerca de la Comisión y su funcionamiento y su impacto en la evolución de la industria ferroviaria del porfiriato.

Es posible que otras razones, por completo independientes de las tácticas utilizadas para establecer las tarifas, fueran responsables de la disminución observada en las tarifas engeneral del porfiriato tardio. El papel de los incrementos resultantesen la proctuctividad de la innovación tecnológica, por ejemplo, debe estudiarse todavía. Igualmente, creo que la continuación de la intensa competencia ferrocarrilera, en especial por el transporte directo, fue el factor más importante. Coatsworth, Impacto, 1984, p. 82.

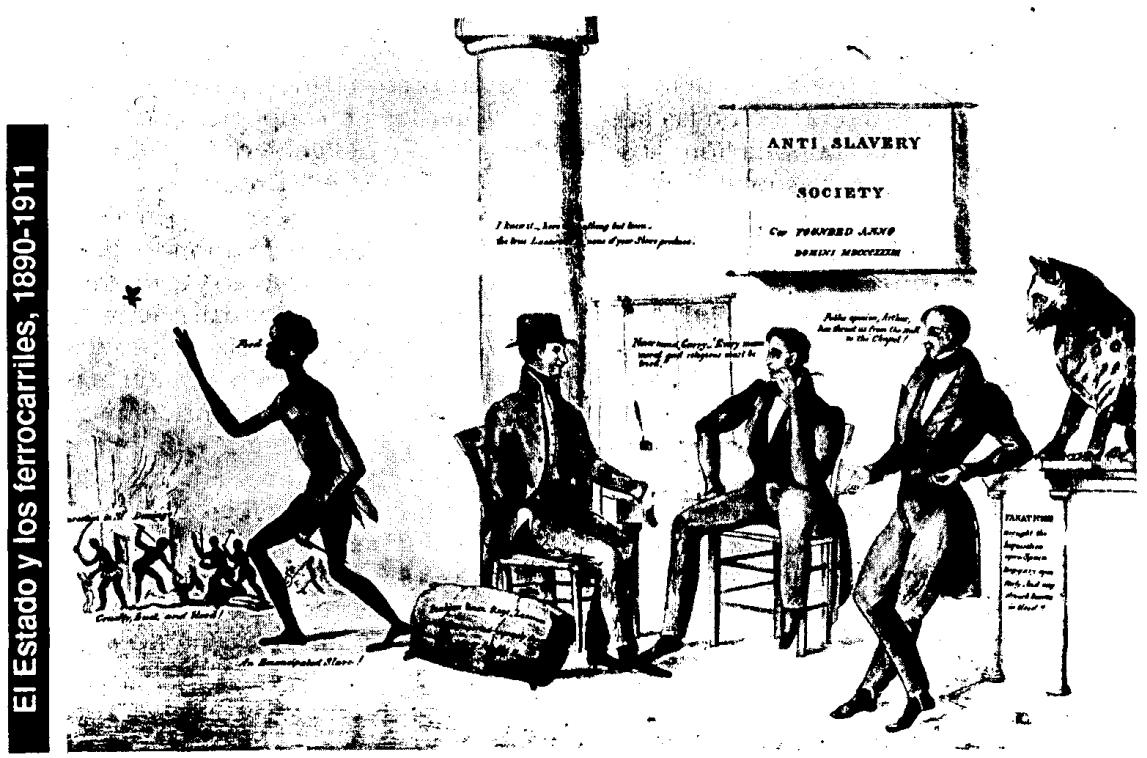


de que se cumplian las penas y se cobraban las multas establecidas por la asociación, abundabanlas acusaciones de fraude. La ejecución de los acuerdos de cooperación fue dificil, en parte porque la Asociación Mexicana de Trấfico "no tenía ningún dominio" sobre las conexiones extranjeras, tanto marítimas como terrestres. ${ }^{54}$ Los representantes en México de estas conexiones "continuamente bajaban sus precios y ofrecían atractivos descuentos a los fletadores, lo que hasta cierto punto anuló la utilidad de la Asociación". 55

En enero de 1900 se llevó a cabo en Nueva York, en la oficina de la Asociación Mexicana de Tráfico, un encuentro entre los ferrocarrileros mexicanos y los representantes de las conexiones marítimas y terrestres, y se formó una nueva asociación con el propósito de fijar límites a las tarifas mexicanas. Pero hay múltiples informes de lo poco efectiva que fue esta decisión. Los acuerdos se quebrantaron continuamente entre 1900 y 1902. El Mexican Herald constantemente reportaba la alteración en las tarifas para la carga de importación. Los Ferrocarriles Central y Nacional se retiraron oficialmente del acuerdo sobre importaciones de Estados Unidos al final de 1902 y en la primera mitad de 1903.56

El meollo del asunto residía en que la única línea totalmente terrestre-El Nacional-se resistía a aceptar que los precios del transporte combinado marítimo-terrestre fueran más bajos que los suyos. Para minimizar esta desventaja constantemente el Ferrocarril Nacional violaba los acuerdos ofreciendo descuentos secretos a los fletadores, para así atraer tráfico a sus líneas.

\footnotetext{
${ }^{54}$ Mexican Herald, 11 de enero de 1901.

ss Ibid.

${ }^{56} \mathrm{Ibid}$.
}

Conforme las compañías mexicanas se dieron cuenta de los tremendos obstáculos que conllevaba reducir la compe. tencia mediante pools y acuerdos sobre tarifas fijas, aun contando con la legislación adecuada, se vieron obligados a recurrir a la estrategia de la consolidación y a formar sistemas. Al concluir el siglo, en México se empezó a sentir el impacto de la reorganización y la consolidación que se había vivido desde 1893 en Estados Unidos.

El Ferrocarril Central y el Nacional fueron los principales rivales en el control de las líneas estratégicas, como parte de sus esfuerzos por construir un sistema. La batalla originada por esta rivalidad se ha estudiado muy ampliamente en la historiografia. ${ }^{57}$ Pero la confrontación que se dio para lograr formar un sistema en México, no se ha interpretado adecuadamente como el resultado de los problemas de competencia (surgidos en gran parte por las características estructurales de las líneas) y de lo limitado de las estrategias usadas para resolverlos, sino como acuerdos de cooperación bajo la reglamentación del gobierno.

Para 1901-1902, el Ferrocarril Central, dirigido por el empresario petrolero Henry Clay Pierce, logró monopolizar todas las rutas entre Tampico y el interior del país. A su vez, el Ferrocarril Nacional, controlado por Speyer y Cia. se reorganizó, de manera que pudiera resultar más competitivo -sobre todo considerando el nuevo sistema del Central-, ampliando su estrecha cobertura y adquiriendo una serie de líneas estratégicas y, para asegurar el tráfico terrestre en la frontera con Estados Unidos se adelantó a su rival en el control del Ferrocarril Internacional. Con esta jugada, controlaba entonces las

\footnotetext{
${ }^{57}$ Calderón, "Ferrocarriles", 1965; Ortiz Hernán, Ferrocarriles, 1987; Parlee, Porfirio, 1981.
} 
dos rutas más cortas para el tráfico internacional entre el centro y el noreste de México y Estados Unidos.

Una de las mayores desventajas del Ferrocarril Nacional era la carencia de conexiones con el Golfo de México. Como ya se explicó, esta limitación incidió negativamente en el tráfico que recibía, en las ganancias que percibía de los pools y en los acuerdos sobre tarifas fijas de la Asociación Mexicana de Tráfico.

Era imposible construir una nueva línea hacia el Golfo dada la posición del gobierno de mantener vigente el plan de Limantour de 1898. La única posibilidad entonces era adquirir una de las líneas ya existentes y esto se pudo realizar cuando a mediados de 1902 el Ferrocarril Interoceánico puso a la venta algunas de sus acciones. Parte del estímulo para la consolidación y la fusión se dio como una consecuencia, quizá no planeada, del programa de restricción a la construcción y al subsidio de nuevas líneas.

Tan pronto como se supo de la oferta del Interoceánico, el Central y el Nacional comenzaron a maniobrar para asegurarse la adquisición de la estratégica línea británica del Golfo. Mientras esto sucedía, las finanzas de ambas compañías se iban deteriorando conforme se desplomaba el precio de la plata hasta el punto más bajo al que cayó durante todo el porfiriato.

La Asociación Mexicana de Tráfico solicitó un aumento general del $50 \%$ para las tarifas, además de su adecuación a la fluctuación de la moneda. Esto desató las protestas de casi todas las compañías mexicanas de fletadores. De hecho, la hostilidad de los fletadores hacia los transportistas alcanzó su punto máximo en la segunda mitad de 1902.

Varias asociaciones mexicanas mercantiles y agrícolas vociferaron en contra de la "política de rapiña" de los fletadores y exigieron la intervención del gobierno. Llegaron incluso a sugerir que éste adquiriese parte de la propiedad. ${ }^{58} \mathrm{Con}$ estas presiones, el gobierno concedió un aumento del $15 \%$ por tres meses, excluyendo los artículos de consumo básico y las exportaciones. ${ }^{59}$

La visita de Harriman a México en los primeros meses de 1902 coincidió con todos estos acontecimientos. Se dice que durante una entrevista con Díaz y Limantour, el líder y constructor de sistemas de los ferrocarriles de Estados Unidos enumeró las múltiples ventajas que traería la consolidación de las líneas mexicanas. ${ }^{60}$

A estas alturas el gobierno, guiado por Limantour, inició su táctica de controlar la compra de acciones. En su reporte de Dieppe del 30 de julio de 1903, Limantour explica cómo y por qué el gobierno inició la compra de acciones ferroviarias. $^{61}$

Para Limantour el problema financiero seguía siendo lo más importante a considerar. Pero los fenómenos relacionados con las "líneas paralelas innecesarias" y la "competencia destructiva" se le hicieron cada vez más importantes, y hace énfasis en las implicaciones que

58 Sobre esto ver los textos citados en la nota anterior y los numerosos artículos publicados en los años 1900-1902 en el Mexican Herald, 1900-1902.

59 AGN AHSCT, Ferrocarriles, carpetas 10/2322-1, 10/90-1, 10/210-1. Esto corrobora la tesis de Knight de que hubo un florecimiento del nacionalismo económico en la elite del porfiriato tardío. Seguramente, la percepción de los fletadores mexicanos sobre las compañias extranjeras de ferrocarriles tenía mucho que ver con el surgimiento de estas ideas en ciertos miembros de la elite del porfiriato tarcío. Para la declaración de los fletadores, consultar varios artículos publicados en los ejemplares de 1902 de La Semana Mercantily el Boletín de la Sociedad Agricola Mexicana.

${ }^{60}$ Mexican Herald, 3-10 de marzo de 1902; Turner, Barbarous, 1969, pp. 238-239; Callahan, American, 1967, pp. 520-521.

${ }^{61}$ Trentini, Florecimiento, 1906, pp. 182-185. 
tienen en las finanzas públicas nacionales. ${ }^{62}$

De acuerdo con el secretario de Hacienda, la existencia de vías férreas paralelas en rutas que sólo podían generar tráfico redituable para una línea, había tenido una serie de efectos perniciosos que afectaban los intereses de todos los involucrados. Aparte de las penosas consecuencias para los inversionistas extranjeros, lamentaba las pérdidas por el daño que ocasionaban al propio público mexicano.

El valioso capital que se malgastaba "podía haberse utilizado en algo mejor, por ejemplo, en abrir regiones en donde aún se necesita la comunicación del ferrocarril y que están aisladas todavía del resto del pais". ${ }^{63}$ Limantour añadía el comentario de que

cuando se pierde el dinero de gente que compra acciones y bonos de empresas tan importantes como los ferrocarriles, el crédito de una nación se ve afectado como posible destino para las inversiones, $y$, por otro lado, uno no debe ignorar el hecho de que los extranjeros juzgan la prosperidad de un país según la cotización de los bonos de la deuda pública y de las acciones de las compañías ferrocarrileras. ${ }^{64}$

Admitía que, en un principio, los fletadores y consumidores mexicanos se vieron beneficiados con la reducción en las tarifas causada por la libre competencia. Sin embargo, argumentaba lo efimero de estas ventajas que pronto se verían anuladas por los serios inconvenientes que conllevaban. Explicaba que

después de poco tiempo la batalla cesa ya sea porque las compañías rivales llegan a

\footnotetext{
62 Ibid., p.182.

${ }^{63}$ Ibid.

G4 Ibid.
}

un acuerdo o bien por la aniquilación completa de una de ellas, pero en ambos casos no hay otro resultado que el alza de las tarifas, que serán mayores que las que existían cuando había guerra de precios, para poderse resarcir de las pérdidas. ${ }^{65}$

Limantour entonces señalaba que las guerras de precios no sólo llevaban a la bancarrota que dañaba seriamente el crédito de la nación, sino que también terminaban a veces en la combinación de las compañías y en otras formas colusorias de acuerdos sobre las tarifas. Según su reporte, Limantour estaba convencido "por la información más confiable y por evidencia indiscutible" de que "un grupo de capitalistas extranjeros planeaba llevar a cabo la consolidación de los principales ferrocarriles [mexicanos]". ${ }^{66}$

En consecuencia, a fin de proteger los intereses de México, el gobierno debía intervenir "sin tardanza" para poder enfrentar "dicha coalición en la forma más valiente" y para prevenir que los ferrocarriles de la nación "cayeran en manos de esta gente". ${ }^{67}$

Existe amplia evidencia que sugiere que Limantour y el gobierno mexicano estaban muy preocupados por las actividades de Henry Clay Pierce como director del Ferrocarril Central Mexicano. Pierce se distinguió tanto en Estados Unidos como en México por ser un empresario incontrolable. $Y$ a pesar de que la compañía petrolera Waters-Pierce en teoría era parte de la Standard Oil Trust, esta última continuamente se quejaba de la actitud poco cooperativa de Pierce. No sabía jugar en equipo. ${ }^{68}$

${ }^{65}$ Ibid.

${ }_{66}^{66}$ Ibid.

${ }^{67}$ Ibid., p. 183.

${ }^{68} \mathrm{Hidy}$, Pioneering, 1955 , pp. $41-42,46-47,219-$ $222,293,310$. 


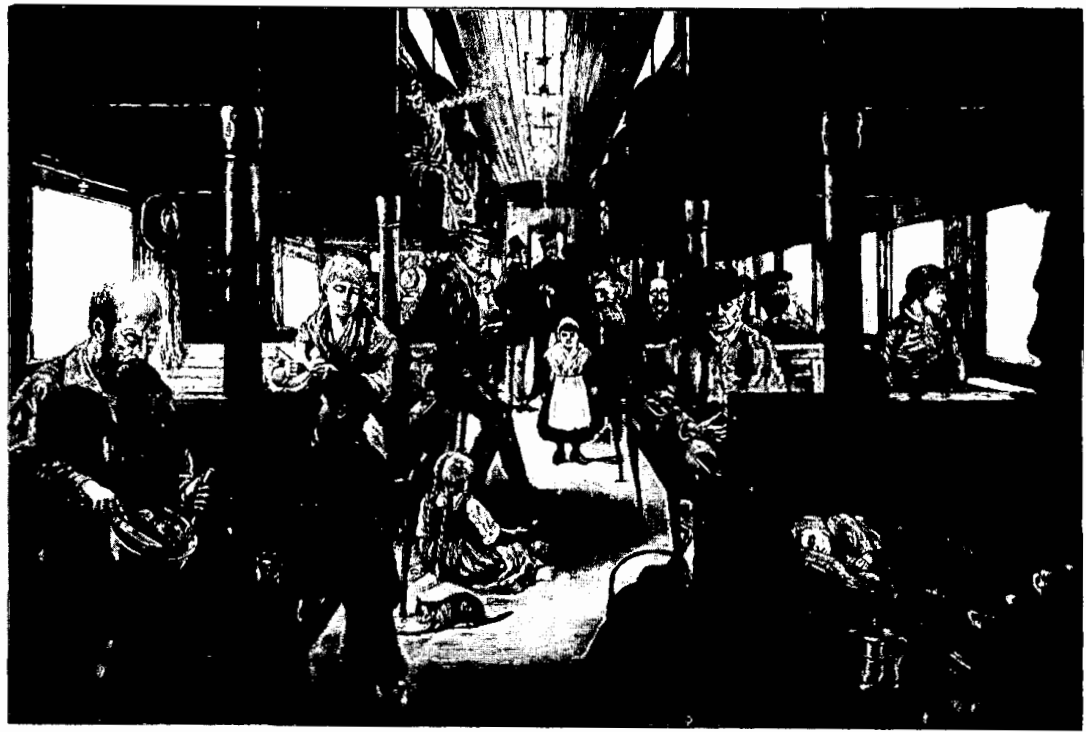

Por añadidura, varios procesos legales bien fundamentados en su contra por actividades monopólicas en Texas y en Missouri demostraban lo poco que le importaba a Pierce la reglamentacióngubernamental. Al inicio del siglo, Pierce consolidó en México el monopolio del refinamiento del petróleo y su distribución. Para completar todo esto, Pierce le desagradaba a Limantour en lo personal tanto como sus agresivas tácticas de negocios. En trabajos recientes se revela que la promoción que dio el gobierno mexicano a la compañía petrolera de lord Cowdray, El Águila, fue un ardid para terminar con el domino prácticamente absoluto de Pierce sobre la venta de productos petroleros en México. ${ }^{69}$

69 Thorup, "Competencia", 1982, pp. 599-641; Brown, "Domestic", 1987, pp. 387-416.
Según Limantour, los mecanismos de reglamentación existentes no proveían los suficientes medios para evitar una consolidación privada y/o sus efectos. Aunque tanto los contratos de concesión. como las leyes ferroviarias incluían cláusulas para la reglamentación de los acuerdos ferrocarrileros, ninguno había previsto "las innumerables combinaciones financieras y comerciales capaces de anular las medidas del gobierno para proteger los intereses nacionales". ${ }^{70}$ Destacan entre estas maniobras de evasión, el control en la compra de las acciones y las direcciones entrelazadas. Además, a pesar de sus logros iniciales, la Comisión Revisora de Tarifas no había reunido aún la suficiente experiencia y fuerza para enfrentar a una corporación

${ }^{70}$ Trentini, Florecimiento, 1906, p. 183. 
tan poderosa. Encima, el gobierno temía que mientras las tarifas máximas legales, según lo estipulado en los contratos de concesión, no se habían alcanzado, si pudieran aumentar bajo un régimen de fusión monopolista. Por lo tanto, el gobierno se vio obligado a diseñar un nuevo plan de acción. ${ }^{71}$

Limantour relató con mucho orgullo cómo decidió, siendo el representante del gobierno, vencer a las compañías jugando su propio juego. La estrategia, como la describió él mismo, consistía "sencillamente en usar su mismo procedimiento, el que utilizan las compañías absorbentes". Así, entre diciembre de 1902 y marzo de 1903 , inició un "valiente programa"72 que facilitara al gobierno la compra de acciones para controlar los ferrocarriles.

El 25 de septiembre de 1902 el gobierno ganó la carrera a Speyer y Cía. en la subasta de acciones del Ferrocarril Interoceánico. Un año después de adquirir control sobre las líneas del Golfo, siguiendo a un periodo de negociaciones, el gobierno mexicano accedió a intercambiar sus acciones del Ferrocarril Interoceánico por $47.5 \%$ de las acciones del Ferrocarril Nacional. Para finales de 1903, el gobierno, en sociedad con Speyer, controlaba un sistema que incluía al Ferrocarril Nacional, al Internacional y al Interoceánico. ${ }^{73}$

\section{${ }^{71} \mathrm{Ibid}$.}

72 Ibid.

${ }^{73}$ Se dio cuenta de que el Ferrocarril Interoceánico, que conectaba la ciudad de México con Veracruz, era la clave de la rivalidad entre los dos sistemas más importantes que estaban surgiendo, el Ferrocarril Mexicano Central y el Ferrocarril Nacional. Actuando en representación del gobierno, Limantour procedió a manifestarse en contra del Ferrocarril Central y el Nacional en su lucha por apoderarse del Interoceánico. Según él, manejó hábilmente la subasta del Ferrocarril Interoceánico, y adquirí 500000 acciones de los votos de
El reporte de Dieppe de 1903 describe estas medidas como esencialmente encaminadas a prevenir la monopolización del sistema nacional de transporte por algún trust norteamericano. Considerando su preocupación de que "un trust o intereses combinados puedan fácilmente controlar todos los elementos de transporte del país", el gobierno actuóen "defensa propia". ${ }^{74}$

Limantour también señalaba que el gobierno había reforzado los "Poderes Públicos Reglamentarios" al convertirse en el principal accionista de los sistemas rivales. ${ }^{75} \mathrm{La}$ idea era usar la propiedad del gobierno como medio para evitar tanto las destructivas guerras de precios como los costos de carga excesivos. Según las palabras del propio secretario:

adquiriendo preponderancia en la representación de varias compañias ferrocarrileras, el gobierno podrá constituir un sistema de líneas que por su gran alcance y la gran extensión de tierras que atraviesan, tendrán influencia en todos los caminos del país, lo que será benéfico para todos. Nos llevará a terminar las hostilidades y permitirá que el tráfico fluya por canales naturales, con tarifas más bajas en general, beneficiando así al público en general con las economías que resulten al cumplirse todos estos objetivos. ${ }^{76}$

control, ganándole asíla carrera a Speyer y Cía., que manejaba al Nacional. Sin haber podido apoderarse del Interoceánico, el Nacional inició negociaciones encaminadas a intercambiarle al gobierno acciones de igual valor del Nacional por sus acciones del Interoceánico. Speyer y Cía. accedió también a formar un bloque común de acciones que aseguraba al gobierno un $47.25 \%$ del total de acciones, lo que le daba el control de las líneas, incluyendo al Ferrocarril Nacional. Como explicaba Limantour, el quid pro quo era la concesión de derechos exclusivos para la construcción a lo largo de la frontera noreste, entre Laredo y Matamoros.

${ }^{74} \mathrm{Ibid}$., p. 184.
${ }^{75} \mathrm{Ibid}$, p. 185.
${ }^{76} \mathrm{Ibid}$., p. 184. 
¿Hasta qué punto se alcanzaron estas metas? ¿Qué efecto tuvo el control del gobierno sobre los Ferrocarriles Nacional y Mexicano entre 1902 y 1908 ?

Es evidente que el objetivo del gobierno de detener una consolidación privada del Nacional y el Central "fue obstaculizado gracias a que el gobierno adquirió el control de una de las corporaciones". 7

$\mathrm{He}$ descubierto, sin embargo, suficiente evidencia sugerente de que los esfuerzos por mantener y aumentar el control sobre la competencia fallaron, sobre todo, entre 1903-1905. La información indica, de hecho, que las tensiones por la competencia se agudizaron después de que el gobierno había alcanzado el control del Sistema Nacional Interoceánico.

Las relaciones eran particularmente tensas entre el sistema del Nacional, dominado por el gobierno, y su principal competidor, el Ferrocarril Central Mexicano. Los puntos de conflicto eran, sobre todo: las violaciones continuas a los tratados internacionales de tráfico, que casi provocaron la ruptura de la Asociación Mexicana de Tráfico; ${ }^{78}$ un agresivo intento de Speyer, socio del gobierno, para tratar de controlar al Ferrocarril Central Mexicano; ${ }^{79}$ y la negativa rotunda del gobierno, en especial de Limantour, para aceptar una propuesta de reforma a los estatutos del Ferrocarril Central Mexicano que tendía a perpetuar el control de Pierce ${ }^{80}$ Las tensiones se dieron en el contexto del deterioro de las condiciones financieras,

\footnotetext{
77 Ibid.

${ }^{78}$ Financial Times, 19 de noviembre de 1904; Soutb American Joumal, 10 de diciembre de 1904; Mexican Herald, 19 de febrero de 1904.

${ }^{79}$ Mexican Herald, 16-17 de junio de 1904.

${ }^{80}$ AGN,AHSCT, Ferrocarriles, carpetas 17/102-2, $103176-4$.
}

operativas y competitivas del Ferrocarril Central. ${ }^{81}$

A finales de 1905la tendencia al conflicto empezó a cambiar. Según lo demuestra su discurso al Congreso en $1906^{82}$ y su Informe de $1908,{ }^{83}$ Limantour estaba al tanto de las consecuencias indeseables de la libre competencia y temía en especial la posibilidad de competir en contra de un ferrocarril que funcionara bajo un sistema de sindicatura, ${ }^{84}$ con la obligación de cubrir los costos fijos suspendidos temporalmente. ${ }^{85}$ El estilo de Pierce para negociar y sus tensas relaciones con algunos miembros del gobierno mexicano aumentaban las probabilidades de tener que enfrentar esta posibilidad. Sin embargo, a pesar de su enemistad con Pierce, Limantour trató de evitar la bancarrota del Central porque le preocupaba el impacto que ésta podía tener en las finanzas de México. ${ }^{86}$

I a gerencia del Ferrocarril Central por fin aceptó que el Nacional era una compañía superior y que una reconciliación sería útil para sus propios intereses. Como consecuencia, a principios de 1906 comenzaron las negociaciones entre el Ferrocarril $\mathrm{Na}$ cional, el Central Mexicano y el gobiemo para dar el siguiente paso lógico: la fusión y la consolidación. El proceso concluyó con el acuerdo de consolidación en 1906 , y con la incorporación de los Ferrocarriles Nacionales de México en 1908.

Además de evitar la consolidación de alguna compañia extranjera, el reporte de 1908 especifica otros objetivos para la formación de Ferrocarriles Nacionales de

\footnotetext{
${ }^{81}$ Mexican Herald, 22 de octubre y 14 de noviembre de 1905 .

82 "Discurso al Congreso", AGN,AHSCT, Ferrocarriles, carpeta 10/89-1.

${ }^{83}$ SHCP, Informe, 1908.

${ }^{84}$ Sindicatura: encargo de cuidar los intereses de una corporación.

${ }^{85}$ Ibid.

${ }^{86}$ Ibid.
}

1 0 1 
México: eliminar la competencia destructiva entre los dos sistemas; tomar ventaja de la economía administrativa que resultaba de la consolidación y finalmente, facilitar la reorganización que permitiese obtener el capital necesario para dar mantenimiento y extender las líneas. A pesar de su discurso nacionalista y en contra de los monopolios, Limantour abiertamente consideraba la protección de la inversión extranjera en los ferrocarriles como una prioridad para el gobierno.

Teóricamente su posición no resultaba contradictoria porque aseguraba que, bajo la propiedad mayoritaria del gobierno, los fletadores y los consumidores nacionales cosecharían parte de las ganancias del sistema con las bajas tarifas y el servicio mejorado. ${ }^{87}$
Limantour afirmaba que, para lograr estos propósitos, seguía algunas de las estrategias usadas por empresarios y negociantes norteamericanos. Así, por ejemplo, intentó tomar ventaja de los múltiples beneficios de la formación de sistemas (eliminar la competencia ruinosa, la economía administrativa y operativa, la posibilidad de reducir las tarifas, etc.). Al mismo tiempo, pensaba que si el gobierno era el mayor accionista de la empresa, evitaría los abusos económicos y políticos que podían darse en una industria manejada por una poderosa compañía extranjera.8

En otras palabras, no consideraba la consolidación per se como una solución negativa a los problemas ferroviarios de México. Al contrario, dado que a largo plazo la competencia ruinosa dañaría los

${ }^{88}$ Ibid.

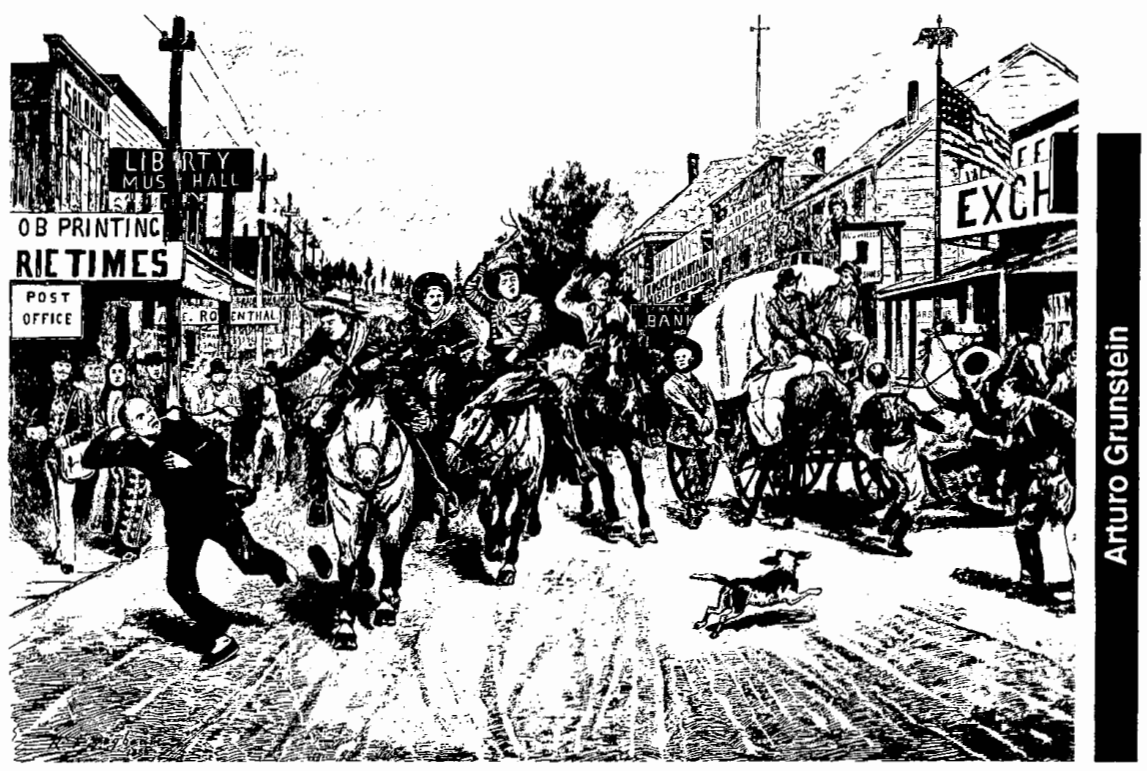


intereses de cargadores y fletadores, la consolidación ofrecía, con las economías del nuevo sistema, el único método duradero para conservar las tarifas y ganancias en una proporción razonable.

En este contexto, entonces, la propiedad y sobre todo el control eran los aspectos claves para el secretario de Hacienda. Un sistema consolidado, poseído y controlado por una compañía extranjera, manejado únicamente mediante un criterio de ganancia, se convertiría en un monopolio. En contraste, el gobierno, como accionista mayoritario, intervendría cuando fuera necesario para equilibrar los intereses de los inversionistas y los fletadores. Más específicamente, Limantour ofrecía que el gobierno utilizaría su control sobre la nueva compañía canalizando equitativamente las economías del sistema consolidado, asegurando ganancias y tarifas razonables.

¿Cuáles fueron las consecuencias de la consolidación del gobierno? ¿Se alcanzaron los objetivos de Limantour? Jaime Gurza, Carlos Díaz Dufoo y el propio Limantour ${ }^{89}$ en sus memorias políticas señalan las utilidades que obtuvo la compañía entre 1909 y 1912 como prueba de que los Ferrocarriles Nacionales de México habían logrado las economías esperadas.

Los críticos $^{90}$ interpretan el éxito financiero inicial de los Ferrocarriles Nacionales de México como la ratificación de que los inversionistas extranjeros habían sido los más beneficiados con la consolidación. Según se dice, las ganancias de la compañía se lograron con tarifas más altas que sacrificaron a los transportistas mexicanos y no como respuesta a las economías planeadas, como sugieren los "limantouristas".

${ }^{89}$ Gurza, Política, 1911; Díaz Dufoo, Limantour, 1910; Limantour, Apuntes, 1965.

${ }^{9}$ González Roa, Problema, 1915; Coatsworth, Impacto, 1984.
Desafortunadamente tanto los críticos como los defensores de Limantour basan sus argumentos en escasa evidencia empírica y convincente. Las consecuencias de la consolidación en cuanto a las tarifas, ganancias, etc., deben analizarse más sistemáticamènte para poder decidir quién se benefició y quién perdió con la integración de Ferrocarriles Nacionales de México. Sin embargo, no cabe duda de que resultó la solución definitiva a uno de los problemas centrales de la evolución de la industria ferroviaria mexicana entre 1890 y 1906. Con este último paso se eliminó toda la competencia ferroviaria en México. ${ }^{91}$

\section{Bibliografía}

-Benson, Lee, Merchants, farmers and railroads: railroad regulation and New York politics, Harvard University Press, Cambridge, 1955.

-Bulnes, Francisco, El verdadero Díaz y la revoluciōn, Ediciones Nacionales, México, 1967.

-Brown, Jonathan, "Domestic politics and foreign investment: british development of mexican petroleum, 1889-1911", Business History Review, vol. LXI, otoño de 1987, pp. $387-416$.

-Callahan, James Morton, American foreign policy in mexican relations, The Macmillan Company, Nueva York, 1932.

-Calderón, Francisco, "Los ferrocarriles", en Daniel Cosío Villegas, Historia moderna de México. El porfiriato. La vida económica, Editorial Hermes, México, 1965, vi.

-Coatsworth, John H., El impactu económico de los ferrocarriles en el porfiriato, Editorial Era, México, 1984.

${ }^{91}$ Después de que tuvo una pequeña dificultad con el Ferrocarril Mexicano en 1909, la scop forzó al Ferrocarril Nacional a formar un pool que abarcara todo. AGN,AHSCT, Ferrocarriles, carpeta 10/31451.

. 


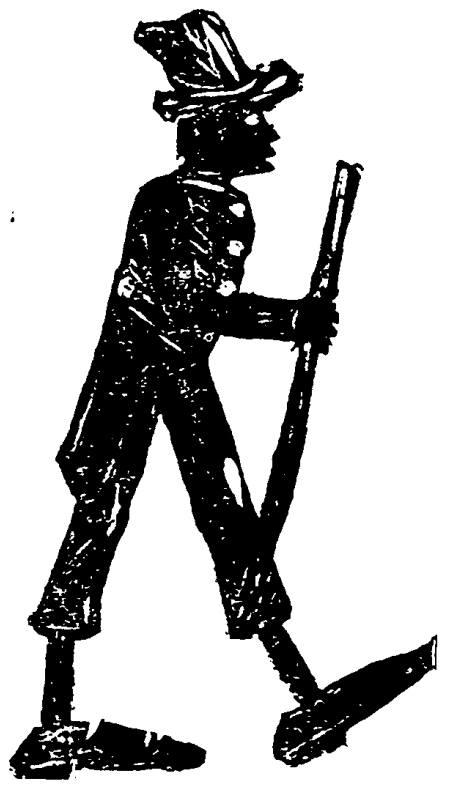

-Chandler, Alfred D., The visible band: the managerial revolution in american business, Harvard University Press, Cambridge, 1977.

-Díaz Dufoo, Carlos, Limantour, Editorial Eusebio Gómez de la Puente, México, 1910.

-Fuentes Díaz, Vicente, El problema ferrocarrilero de México, ed. del autor, México, 1951.

-González Roa, Fernando, El problema ferrocarrilero y la Compañia de los Ferrocarriles Nacionales de México, Editorial Carranza e Hijos, México, 1915.

-Grodinsky, Julius, Transcontinental raitway strategy: 1869-1893: a study of businessmen, University of Philadelphia Press, Philadelphia, 1962.

-Gurza, Jaime, La politica ferrocarrilera del gobierno, Oficina Impresora de Estampillas, México, 1911.

-Hart, John Mason, Revolutionary Mexico: the coming and process of the mexican revolution, University of California Press, Berkeley y Los Ângeles, 1988.
-Hidy, Ralph y Muriel, Pioneering in big business. 1882-1911: a bistory of the Standard Oil Company, Norton, Nueva York, 1955.

-Knight, Alan, "The political economy of revolutionary Mexico", en Christopher Abel y Colin Lewis, (comps.), Latin America: economic imperialism and the state, Cambridge University Press, Cambridge, 1985. U.S.-Mexican relations, $1910-$ 1940: an interpretation, University of California, San Diego, 1987.

-Kolko, Gabriel, Railroads and regulation, 1877-1916, Norton and Co., Nueva York, 1970.

-Limantour, José Ives, Apuntes de mi vida pública, Editorial Porrúa, México, 1965.

-Locklin, D. Phillip, Economics of transportation, Homewood, 1954.

-López Gallo, Manuel, Economía y politica en la bistoria de México, Ediciones El Caballito, México, 1988.

-Martin, Albro, "The troubled subject of railroad regulation in the gilded age: a reappraisal", Journal of American History, vol. IXVI, septiembre de 1974, pp. 339-371.

-McAvoy, Paul W., The economic effects of regulation: the trunkline railroad cartels and the interstate commerce commission before 1900, Cambridge University Press, Cambridge, 1965.

-McNeely, John $\mathrm{H}$., The railways of Mexico: a study in nationalization, Western College Press,El Paso, 1964.

-Ortiz Hernán, Sergio, Los ferrocarriles de México: una visión social y económica. La luz de la locomotora, Ferrocarriles Nacionales de México, México, 1987, t. I.

-Parlee, Lorena M., Porfirio Diaz, railroads and development in nortbern Mexico: a study of government policy towards the central and national railroads, 1876-1910, (tešis doctoral), University of California, San. Diego, 1981.

-Powell, Edward A., "Ideas and interests: businessmen and the interstate commerce act", Joumal of American History, vol. LIV, diciembre de 1967, pp. 561-578.

-Randall, Robert W., "Mexico's pre-revolutionary reckoning with railroads", The Americas, vol. XLII, julio de 1985, pp. 1-28. 


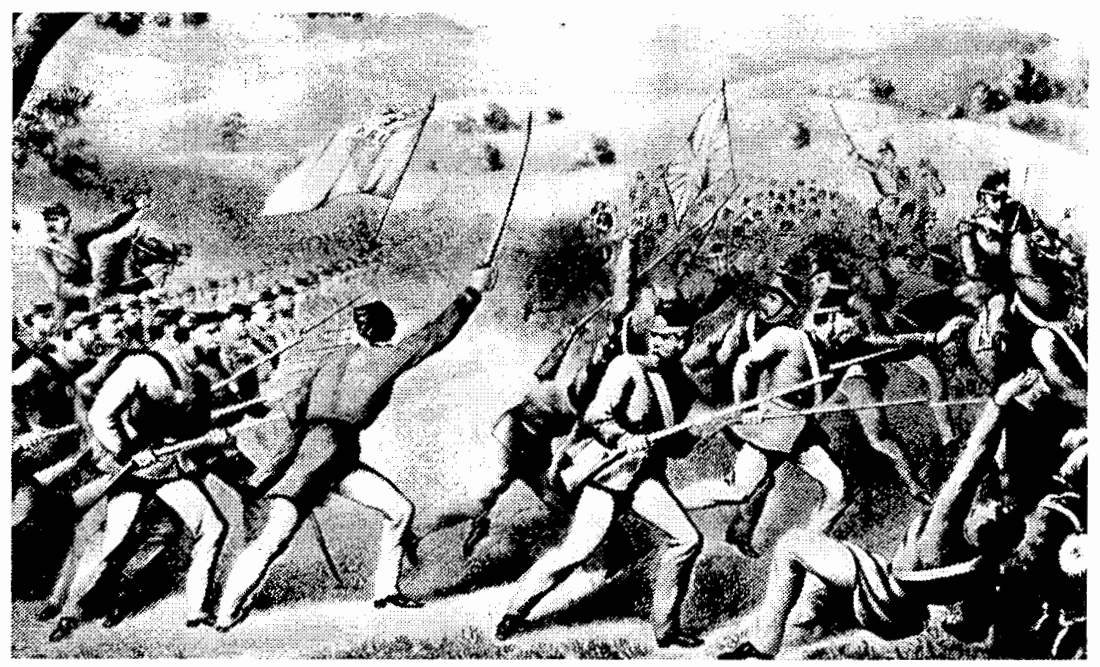

-Ripley, William Z., Railroads: rates and regulation, ed. del autor, Nueva York, 1912. , Railroads: finance and organization, ed. del autor, Nueva York, 1927.

-Schmidt, Arthur P., The social and economic effect of the railroad in Puebla and Veracruz, Mexico, 1867-1911, tesis doctoral, Indiana University, Indiana, 1973.

-Secretaría de Comunicaciones y Obras Públicas, Ley Sobre Ferrocarriles, Talleres Gráficos de la SCOP, México, 1910.

-Secretaría de Hacienda y Crédito Público, Memoria de Hacienda y Crédito Público correspondiente al añoeconómico del 1 de julio de 1898 al 30 de junio de 1899 presentada porelsecretarioJ.I. Limantoural Congresode la Unión, Talleres Gráficos de la SHCP, México, 1902.

Informe presentado al presidente de la república por el secretario de Hacienda y Crédito Público sobre los estudios $y$ gestiones de la Secretaria a su cargo en asuntos de ferrocarriles, Talleres Gráficos de la SHCP, México, 1903.
Informe del secretario de Hacienday Crédito Püblico a las Cámaras Federales sobre el uso de las facultades conferidas al Ejecutivo de la Unión por la ley del 26 de diciembre de 1906, para la consolidación de los ferrocarriles Nacional de México y CentralMexicano, Talleres Gráficos de la SHCP, México, 1908.

-Trentini, Francisco, El florecimiento de México, Ediciones de Estampillas, México, 1906.

-Tischendorf, Alfred, Great Britain and Mexico in the era of Porfirio Diaz, Duke University Press, Durham, 1961.

-Thorup, Cathryn, "La competencia económica británica y norteamericana en México, 1887-1910: el caso Weetman-Pearson", Historia Mexicana, vol. XxxI, núm. 124, abril-junio de 1982, pp. 599-641.

-Turner, John K., Barbarus Mexico, University of Texas Press, Austin, 1969.

-Yeager, Mary, Competition and oligopoly: the development of oligopoly in the meat packing industry, JAI Press, Greenwich, 1981. 


\section{SECUENCIA}

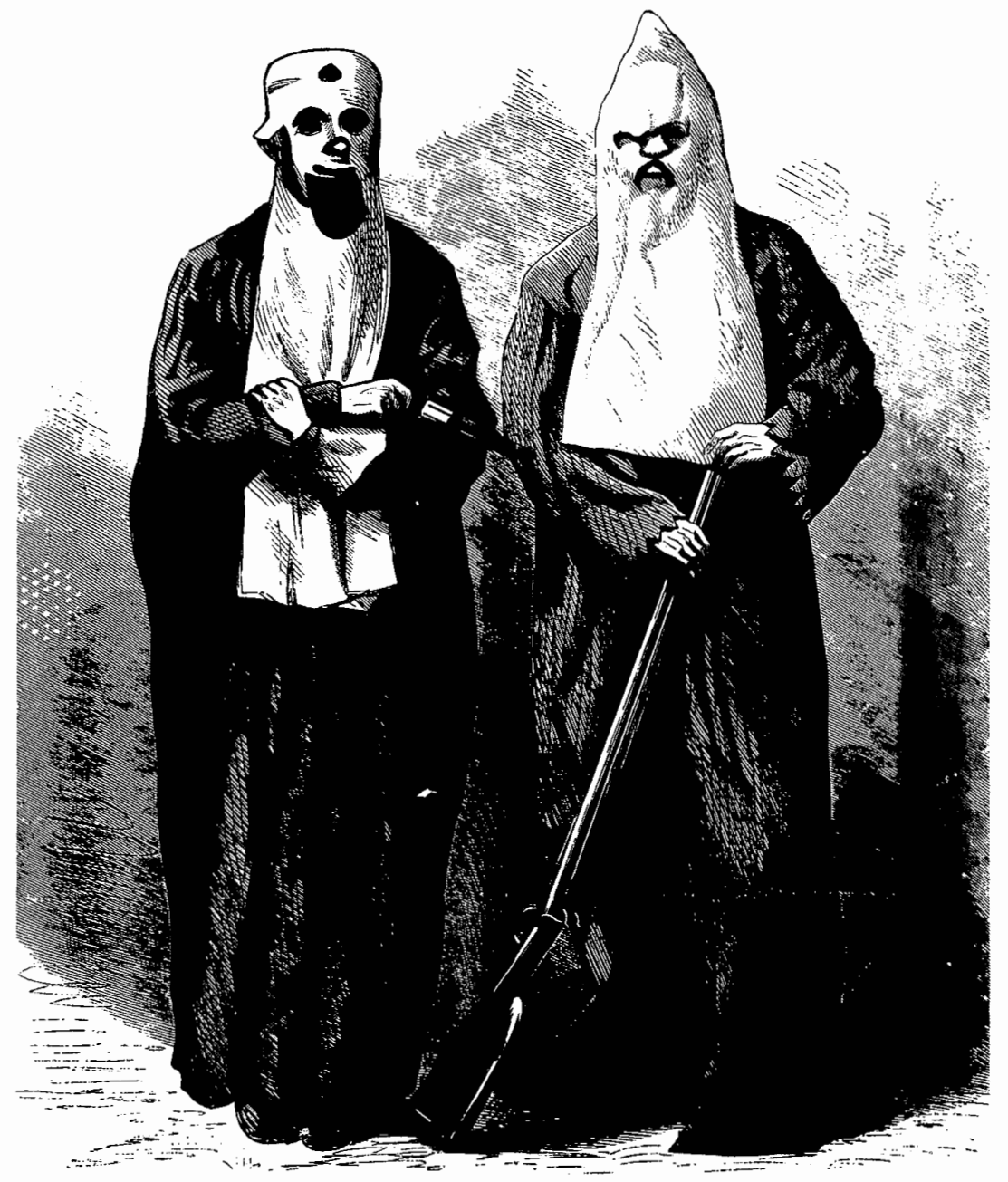

